\title{
Does One Size Fit All? The Consequences of Switching Markets
}

\section{with Different Regulatory Standards ${ }^{*}$}

\author{
Tim Jenkinson \\ Said Business School, University of Oxford and CEPR \\ Tarun Ramadorai \\ Said Business School, University of Oxford, Oxford-Man Institute and CEPR
}

\begin{abstract}
As the regulation of public companies has progressively tightened in recent years, many companies have chosen to switch to stock exchanges with lower regulatory requirements. We analyse the consequences of switching for smaller quoted companies, using the unusual regulatory environment in London, which has two markets with different regulatory regimes but the same trading technology. Firms that switch to lighter regulation experience, on average, negative announcement returns of approximately 5\%. However the initial price reactions are reversed after the actual switch: there is a longerterm upward drift in stock returns. We relate these financial returns to significant improvements in operating performance that we find in the two years following the switch, suggesting that for some companies, and their investors, a lighter regulatory environment may be appropriate.
\end{abstract}

Version: February 2010

JEL classification: G14, G30

Key words: stock markets, listing, regulation, switching

\footnotetext{
* We thank Andrea Randone, Roland Fejfar, Opal Jiang, and Vesa-Heikki Soini for excellent and dedicated research assistance, and seminar participants at London Business School, Helsinki School of Economics, Tilburg University, the CEPR Gerzensee meetings and the American Finance Association 2008 meetings for comments. The views expressed here are ours, and we alone bear responsibility for any mistakes and inaccuracies. Comments welcome to tim.jenkinson@sbs.ox.ac.uk or tarun.ramadorai@sbs.ox.ac.uk .
} 


\title{
Does One Size Fit All? The Consequences of Switching Markets with Different Regulatory Standards
}

\begin{abstract}
As the regulation of public companies has progressively tightened in recent years, many companies have chosen to switch to stock exchanges with lower regulatory requirements. We analyse the consequences of switching for smaller quoted companies, using the unusual regulatory environment in London, which has two markets with different regulatory regimes but the same trading technology. Firms that switch to lighter regulation experience, on average, negative announcement returns of approximately 5\%. However the initial price reactions are reversed after the actual switch: there is a longerterm upward drift in stock returns. We relate these financial returns to significant improvements in operating performance that we find in the two years following the switch, suggesting that for some companies, and their investors, a lighter regulatory environment may be appropriate.
\end{abstract}

JEL classification: G14, G30

Key words: stock markets, listing, regulation, switching 


\section{Introduction}

It is often taken as axiomatic that investors prefer higher levels of regulation of public companies, and in recent years, often following scandals or crises, many countries have progressively increased the level of such regulation. The most notable example of this tendency is the passing of the Sarbanes-Oxley Act in the U.S., but world-wide, stock exchanges have been increasing and tightening their requirements of listed companies in diverse areas, including firms' compliance with codes of corporate governance and the information that listed firms must include in their prospectuses.

At the same time, we see many companies attempting to avoid these regulatory burdens. More highly regulated stock markets in both the U.S. and the U.K. have seen reductions in the number of initial listings, while more lightly regulated markets have been favoured, especially by smaller firms. Recently, there has been a collapse of international listings in the U.S. following the introduction of Sarbanes-Oxley, and some U.S. companies have chosen to float on non-U.S. exchanges. A particularly impressive recent development is the enormous growth of the lightly-regulated Alternative Investment Market (AIM) segment in London, which attracted close to 1,000 new (relatively small) companies during 2005-2006. The recent success of AIM has resulted in other stock exchanges launching similar segments, such as the Alternext market recently launched by NYSE-Euronext, and First North, part of the NASDAQ-OMX group of exchanges, which covers the Nordic and Baltic regions.

AIM's success has also attracted negative attention, prompting calls from the leaders of rival exchanges and regulatory authorities for AIM to raise its regulatory requirements. ${ }^{1}$ This leads us to the question we address in this paper: what are the consequences for companies, and their investors, of switching between markets with different regulatory standards?

\footnotetext{
${ }^{1}$ See, for instance, the article in the Financial Times, 27 January, "NYSE chief says AIM must raise standards", which reports that NYSE chief executive John Thain suggested that "London's Alternative Investment Market lacks stringent corporate governance requirements for listed companies and should keep raising its standards.” Furthermore, on March 9, again in the Financial Times, SEC commissioner Roel Campos is quoted as saying that AIM “...feels like a casino to me, and I believe investors will treat it as such”.
} 
Financial markets are largely defined by regulation and technology. Regulation includes financial services regulation, company law, and the specific requirements imposed by the markets themselves. Technology relates to the trading systems that allow market participants to interact with each other and to establish prices at which to trade. Comparisons between markets are generally difficult as both technology and regulation differ significantly. However, in this paper we consider the impact of regulation in a very direct way, by analysing the experience of companies that switched between markets that differ primarily in their levels of regulation. An important caveat is that the focus in this paper is on the consequences for those companies that chose to switch regulatory regimes, rather than investigating the possible determinants of the switching decision itself.

The two markets that we consider are both part of the London Stock Exchange (LSE). The Main Market (MM) of the LSE comprises securities that have satisfied the requirements of the UK Listing Authority (UKLA). In addition, these companies are subject to further requirements by the LSE. However, the shares of a company can also be traded on the AIM market of the LSE. Companies traded on AIM are not listed, i.e., they do not need to satisfy UKLA's requirements, and the LSE imposes less stringent requirements on them. ${ }^{2}$ As we explain more fully in the next section, the regulatory environment on AIM involves a high degree of self-regulation by the company's nominated advisor, which acts as the main quality control mechanism. Furthermore, companies on AIM face fewer continuing obligations in terms of reporting and corporate governance. While the regulatory environment for the two markets is clearly different, the trading mechanisms used by AIM companies are identical to those used by companies on the MM, and both markets are subject to the same UK legal system that protects the rights of shareholders.

Many countries have second-tier markets, but several features of the UK markets make them particularly suitable for our purposes. First, both markets are well-established and have large numbers of

\footnotetext{
2 The term "listed" is often used to refer to any company quoted on a stock exchange. However, in this paper we focus on the distinction between the regulatory environments of the two London markets, and so we reserve the use of this term for companies that have satisfied the formal listing requirements of the UK Listing Authority (UKLA), which is a part of the Financial Services Authority (FSA).
} 
companies trading on them: at the end of 2006, there were around 800 companies $^{3}$ on the MM, and just over 1,600 on AIM. Of prime importance for our research, there has also been a significant flow of companies switching between the markets. Perhaps surprisingly, the net flow of companies switching markets has been very heavily towards AIM. Our sample comprises 218 companies that have switched “down” to AIM, and 56 companies that switched from AIM “up” to the Main Market.

Second, as noted above, the growth and popularity of AIM has been phenomenal in recent years. Although still predominantly a market that attracts smaller companies, over a quarter of AIM companies have market valuations above $£ 50 \mathrm{~m}(\$ 75 \mathrm{~m})$. AIM has attracted a growing number of overseas companies onto its market: nearly 400 foreign companies were quoted on AIM at the end of 2006. In contrast to the 500 new companies joining AIM per year during 2005 and 2006, the MM attracted, on average, only 19 IPOs per year during this period. ${ }^{4}$ Consequently, our research has the additional benefit of shedding light on the factors that have made AIM so attractive to companies, both domestic and foreign.

Third, unlike some other markets where the exchange can "de-list" a company for failing to comply with one or more of its standards, the LSE has few ongoing standards (e.g., minimum market capitalisation requirements) that result in companies being obliged to move down to AIM. The main exception is the requirement that at least $25 \%$ of the share capital of a firm should be in public hands. Except for five of the companies that moved to AIM, the switch was a deliberate choice by the firm, rather than a condition imposed upon them by the LSE. The decision to switch markets was at the discretion of the management, and did not require shareholder approval. This does raise the prospect that there may be agency issues involved, and biases us against finding that switching to AIM is beneficial for firms, despite

\footnotetext{
${ }^{3}$ The headline figure for the number of Main Market companies is considerably higher: there were 1276 entities traded at the end of 2006. But if financial vehicles, such as investment trusts, and duplicate securities, such as preference or convertible shares, are excluded, the number of distinct trading companies falls to around 783.

${ }^{4}$ This figure excludes financial entities (classified by the LSE as equity investment instruments, investment companies, investment entities and real estate).
} 
strong statements by their leadership about the cost-benefits experienced by firms as a consequence of lighter regulation. ${ }^{5}$

Finally, trading and accounting information on switching firms is readily available in London's markets. Liquidity does not differ much as companies switch between AIM and the MM, which stands in contrast to the U.S., where moving off the major exchanges often leads to a collapse in trading activity. Furthermore, while U.S. companies often "go dark" (stop reporting accounting information) following SEC deregistration, there is no such issue in the U.K., as all companies are required to publish this information regardless of whether they are subject to UKLA regulation or, for that matter, traded on a stock exchange. This enables us to analyse the immediate impact of switching markets and regulatory standards on share prices as well as on longer-term firm operating performance.

To summarize our main results, we find significant announcement effects associated with the decision to switch market segments. Companies moving from AIM to the MM experience significantly positive announcement returns, of approximately $5 \%$ on average. Thereafter, performance is broadly neutral, although some forms of risk-adjustment generate mildly negative returns. Companies switching from the MM to AIM experience similar, but opposite, announcement effects averaging around $-5 \%$. However, this is not the end of the story. Once these companies actually start trading on AIM, average returns are strongly positive, with cumulative abnormal returns approaching $+25 \%$ one year following the switch. The net result viewed over this longer event window is, therefore, strongly positive.

We investigate various possible explanations for this pattern of returns, including whether operating performance changed post-switch. We find significant improvements in performance in the two years following the switch to the less regulated AIM environment, which is consistent with the general pattern of shareholder returns, and suggest that investors did not fully anticipate the impact of switching to

\footnotetext{
${ }^{5}$ As an example - albeit more strongly expressed than most - of the reasons given for switching to AIM, the Chairman and Chief Executive of Arbuthnot Banking Group explained to the Financial Times why the company, having been listed on the MM for 17 years, was switching to AIM: “AIM ... offers a lighter regulatory touch ... it will provide some relief from the regulatory onslaught that is costing us $£ 1.25 \mathrm{~m}$ a year - a lot for a company whose profits last year were £5.5m.” (Financial Times, July 14, 2005).
} 
AIM at the time of the announcement. Our results suggest that the most suitable regulatory regime may differ across companies, and that the management of the smaller quoted companies that switched to AIM were not, in general, acting against the interests of their shareholders.

The remainder of the paper proceeds as follows. The remainder of this section reviews related literature. In the next section we describe the regulatory environment existing in London, and explain how this is well-suited as a test-bed for our research. In Section 3 we provide summary information on the development of the two market segments. We also describe how our sample was constructed, and give some descriptive statistics on the switching companies. Section 4 analyses the impact that switching markets has on stock returns using event study methodology. Section 5 focuses on the longer-term financial performance of firms in the two years after they switch markets. Section 6 concludes.

\subsection{Related Literature}

The results in this paper relate closely to prior work in a number of different areas. There is a wellestablished literature examining the various costs and benefits associated with regulation, in particular financial reporting and disclosure rules (for an interesting survey of this literature see Leuz and Wysocki (2008)). Changes in regulatory rules have often been the focus of such research, for instance the impact of the U.S. Securities Act of 1933 and the Exchange Act of 1934 (Stigler (1964), Benston (1973), Simon (1989), Mahoney and Mei (2006)), the 1964 Securities Acts Amendments (Ferrell (2004), Greenstone, Oyer and Vissing-Jorgenson (2006)) and the more recent adoption of Regulation Fair Disclosure in 2000, and the 2002 Sarbanes-Oxley Act (Coates (2007), Leuz (2007)). While different authors arrive at different conclusions, in general this literature suggests that policymakers' enthusiasm for tighter regulatory standards is not matched by unambiguous evidence that the benefits outweigh the costs. Furthermore, some authors have recently cautioned that the optimal amount of disclosure and reporting is likely to vary across firms (see, for instance, Bushee and Leuz (2005), Iliev (2007)), while others (Duarte, Kong, Young and Siegel (2008)) argue that there was no differential response for small and large firms to the introduction of Sarbanes-Oxley. Our paper contributes directly to this debate, and suggests that one-sizefits-all regulation could impose significant costs on small firms. 
In addition to the literature on the impact of regulation, a few previous studies have analysed the consequences of switching markets for firm performance. For instance, Angel et. al. (2004) focus on those companies that were forced to de-list from Nasdaq and ended up being traded on the Pink Sheets. ${ }^{6}$ They found that "trading down" to the Pink Sheets cost shareholders dearly. However, the Pink Sheets are essentially a quotation service where only broker-dealers can apply to make a market in the securities, rather than a stock exchange. In contrast, although lightly regulated, AIM is a market segment of one of the world's leading stock exchanges, and shares common trading technology with the Main Market. ${ }^{7}$ Furthermore, the companies we study chose to switch market segments, rather than being forced to switch as a result of either violating existing rules or the imposition of more stringent rules. The only real complexity in comparing across the two markets in our study arises from the need to investigate the potential impact of the tax consequences of switching between the Main Market and AIM - which we find does not significantly impact our results.

Another related literature with relevance to this paper considers the impact of listing companies on foreign exchanges. In most cases, companies list on foreign exchanges after having conducted IPOs on their local exchanges. The main motivations for these cross-listings that have been suggested in the academic literature include increased liquidity, reducing market segmentation, and a variety of potential corporate governance benefits associated with committing to more stringent legal, regulatory or disclosure rules and thereby overcoming potential agency conflicts (Stulz (1999)). The ultimate effect of cross-listing

\footnotetext{
${ }^{6}$ It should be noted that the quotation services offered by the Pink Sheets and the Nasdaq Over-the-Counter Bulletin Board (OTCBB) in the U.S. differ from AIM in some important respects. As noted by Macey and O’Hara (2004), the Pink Sheets and OTCBB do not provide issuer listing services but rather provide a quotation service to market makers. In regulatory terminology, Pink Sheets is considered a "non-exclusive securities information processor and inter-dealer quotation system”, and is neither an SEC registered exchange nor an NASD regulated broker/dealer (source: www.pinksheets.com), and the OTCBB is a "regulated quotation service" for equity securities that are not listed or traded on Nasdaq, NYSE, or any other national securities exchange. In contrast, AIM is a market run by the London Stock Exchange, upon which companies can conduct IPOs, can be included in benchmark indices and can be traded using the trading technology provided by the LSE.

${ }^{7}$ Changes to trading technology have been shown to have significant impacts on stock prices. See Jain (2005) and Easley, Hendershott and Ramadorai (2009) for two recent examples.
} 
should show up in the cost of capital, and hence many studies adopt an event study methodology as we do. However, in recent years a number of papers have pointed to the potential drawbacks of cross-listing, including information asymmetry problems, increased cost of compliance with foreign corporate governance and legal systems etc. (see Karolyi (2006) for an excellent survey). The context for this somewhat more sceptical view of the costs and benefits of cross-listings has been the dramatic decline in the number of cross-listed companies. For instance, Karolyi (2006) reports that between 1997 and 2002 the global number of cross-listed stocks fell by more than $50 \%$.

The number of cross-listings has indeed been falling on London's Main Market in recent years, as well as on the New York exchanges. However, AIM has bucked this general trend and, as noted above, has been attracting overseas listings in increasing numbers. Furthermore, the share of US markets in global IPOs has fallen sharply: Zingales (2006) estimates that the US markets were capturing nearly onehalf of all global IPOs in the late 1990s, but only around 8\% in 2006. These developments have led to an interesting debate about whether New York is losing competitiveness to London, in particular since the passing of the Sarbanes-Oxley Act in 2002. Doidge, Karolyi and Stulz (2007) estimate that the net benefits of a U.S. cross-listing have remained positive and relatively constant in recent years, whereas they find no significant benefit from being cross-listed on the Main Market in London. They acknowledge the huge growth in overseas companies choosing AIM, but note that the small average size of such companies means they were not likely candidates for a US cross-listing.

Our research design enables us to consider such issues from a rather different angle. Rather than compare the relative benefits of listing across countries, where the differences in legal system, taxation, regulation etc. are often complex, and where it is necessary to control for firm characteristics (such as size, industry, etc.), we focus on switches by a given company between market segments within a single country. It is unambiguous that the MM is more highly regulated than AIM. The legal and trading systems are the same. The only complexity arises due to the need to investigate the potential impact of tax-driven strategies for changing market segment, although we find no significant impact arising from taxation. Consequently, although our focus is exclusively on companies trading on the London markets, the 
analysis has broader relevance to the cross-listing debate, and the general policy concern about the impact of regulation - in its various forms - on the competitiveness of markets.

\section{Alternative Regulatory Regimes}

The Main Market and AIM are the two most important markets run by the London Stock Exchange (LSE). Until 2000 the LSE regulated the formal listing requirements for companies, at which point this regulatory function was transferred to the UKLA, itself part of the UK Financial Services Authority (FSA). The Main Market (MM) of the LSE is a regulated market as defined by the EU Investment Services Directive whereas AIM is designated as an exchange regulated market. In practice this means that companies seeking admission to the MM have to obtain prior approval by the UKLA, as well as satisfy the requirements of the LSE. ${ }^{8}$ In contrast, the rules for admission to AIM are entirely determined by the LSE, and the main principle that has been adopted is that companies seeking admission should engage, and obtain the approval of, a nominated advisor (or "Nomad"), who will guide them through the process and certify that they are appropriate companies to be traded on AIM. Nomads tend to be smaller investment banks or corporate finance advisory boutiques; to date the bulge-bracket investment banks have not entered this market.

A summary of the current admissions criteria and continuing obligations for the two markets is presented in Table 1. The table shows that the MM has admissions criteria that are commonly observed at leading stock exchanges, such the requirement to have an established trading record, minimum market capitalisation and free float rules. ${ }^{9}$ The main difference between the two markets is that the MM involves considerably higher levels of compliance, and greater on-going obligations regarding disclosure and transparency. The rules are extremely detailed and prescriptive, and include requirements on the timing,

\footnotetext{
${ }^{8}$ European regulation is converging such that all EU stock exchanges will admit companies to their regulated markets if they have satisfied any recognised EU competent authority for listing.

${ }^{9}$ To quote the LSE, “A primary listing means the company is expected to meet the UK's gold standard - described as super-equivalent to the EU directives and implemented as part of the Financial Services Action Plan - and as a consequence may enjoy a lower cost of capital through greater investor involvement.”
} 
content and frequency of financial reports; the need to publish six-monthly management statements; mandatory compliance with the Takeover Code; the requirement to comply, or explain in a public statement, the extent of any non-compliance with the Combined Code on Corporate Governance; a requirement to notify and/or obtain prior shareholder approval for many types of transactions, including share option plans, secondary issues, and the acquisition or disposal of fixed assets; requirements to issue circulars to shareholders; rules relating to the content of such circulars, and the need to obtain prior approval of the FSA; and a requirement for all management and any employees with access to inside information to comply with the wide-ranging "Model Code” relating to share dealing. This just gives a flavour of the continuing obligations associated with being on the MM, the full details are contained in the FSA Handbook, in particular the chapters relating to Listing Rules and the Disclosure and Transparency Rules. $^{10}$

The rules at the LSE MM are very similar to those that apply at most of the major stock exchanges around the world, albeit with differences in detail, emphasis and legal status. Collectively, these are what we refer to as regulation. For our purposes, the details of these various aspects of regulation are not important; what matters is the contrast with the regulation of firms quoted on AIM.

This contrast is striking. Regarding admission to the market, it is literally possible to create a new company and have it trading on AIM within two to three weeks, provided a Nomad can be found to support the application. The only rules regarding timing are (1) that a company seeking admission to AIM should provide the LSE with basic descriptive information about the company at least 10 business days before the expected date of admission (the "rule 2 announcement"), and (2) that at least 3 business days before admission, an applicant must submit an admission document, a completed application form, and the relevant fee (the "rule 5 application”). Note, in particular, that there are no rules regarding the minimum

\footnotetext{
10 The LSE has a few additional obligations that relate to MM (but not AIM) companies, but these are relatively trivial, relating, for instance, to the need to agree with the exchange about timetables for announcements, dividend declarations, and open offers for shares.
} 
number of shareholders, unlike, for example, the New York Stock Exchange and NASDAQ. These institutions require a minimum of 2,000 and 400 investors $^{11}$ at the time of IPO respectively.

AIM companies also have far fewer continuing obligations than their MM counterparts. The main requirements for AIM companies derive from general company law and securities regulations (including certain aspects of EU legislation, such as the prospectus directive) that apply to all public (but not necessarily listed) companies. Furthermore, much of the regulatory burden on AIM companies is devolved to their Nomads. For example, Nomads must certify that an AIM company is fit to be traded on public markets, and that its management understand their obligations. Until recently, no rulebook existed for Nomads, who were guided only by very general principles. The first rulebook was published in February 2007. ${ }^{12}$ However, this codification of the requirements for Nomads confirms the continued relative lack of regulation of AIM companies, beyond some basic rules regarding providing information to investors in a timely fashion, and abiding by securities regulations regarding insider trading. This lack of formal regulation lies behind the somewhat tendentious comments about AIM noted in the introduction.

During the sample period that we consider (the period from the inception of AIM until the end of 2006) the decision to switch between the MM and AIM could be made by management. This was true both for switches from the MM to AIM (where, perhaps surprisingly, such decisions were not a matter upon which the listing rules required shareholder approval) and for companies switching from AIM to the MM. Of course, for the latter group, the approval of the UK Listing Authority was required. ${ }^{13}$

Why do companies choose to switch market segments, especially those that are choosing to move to AIM? A typical statement (from Bradstock Group plc) emphasizes the regulatory environment on the $\mathrm{MM}$ as a reason to move to AIM:

\footnotetext{
${ }^{11}$ The regulations are formally stated in terms of "round-lot holders" of at least 100 shares.

${ }^{12}$ See the AIM Rules for Nominated Advisors, February 2007, available from the LSE website.

${ }^{13}$ In 2007, the rules were changed so that firms switching from the MM to AIM now need to obtain the approval of a majority of the shareholders before doing so.
} 
"We continue in our endeavours to identify new activities that will enable the Group to develop its business. We are, however, currently restricted in the transactions that we can undertake due to the high costs that would need to be incurred to meet the stringent UKLA rules. We have concluded, therefore, that it would be in the best interests of the Company for it to transfer its listing to the AIM. The AIM rules are less prescriptive than the UKLA's rules and we believe that it is appropriate for the Company to move to AIM to enable it to take advantage of the greater flexibility afforded by that market.”

Other reasons given by a number of firms emphasize the positive benefits of the AIM market. For instance, Abbey plc (a housebuilding company operating in the UK and Ireland, incorporated in Ireland, and previously on the Official Lists of the London Stock Exchange and the Irish Stock Exchange) transferred to AIM in November 2004 and stated:

"AIM is a fast growing market focussed on growing companies. AIM companies enjoy wide investor support. AIM is gradually attracting an increasing number of international companies and is, the Board believes, well placed to become the European market of choice for successful growth companies. All AIM companies, irrespective of their origin, are included in the FTSE AIM index, in direct contrast to the UK FTSE Indices for the UKLA Official List companies which generally exclude non UK registered companies. The inclusion of Abbey in the AIM index should of itself encourage significant additional interest in the Company. The UK authorities continue to support the development and growth of the market, in particular by maintaining a significantly more attractive fiscal regime for UK investors in AIM companies than is accorded to investors in UKLA Official List companies. Overall the regulatory regime attaching to AIM companies is better matched to their circumstances as small successful growing companies than that attaching to the larger companies on the UKLA Official List.” [RNS announcement, 15/10/04].”

This statement is interesting in drawing attention to the possible increased investor interest that might result from being traded on AIM. In part this might result from inclusion in stock market indices, as noted in the above quotation. Consequently, we investigate whether such index-inclusion effects are important in our study. We also investigate whether changes in shareholder composition are observed when companies switch markets. Mention is also made in the above quotation of certain tax differences that exist for companies on AIM relative to the MM. Although the main differences between being on the MM or AIM relate to what we term governance issues, at various times in our sample period there have been some differences in the way in certain investors are taxed, according to whether or not the share were "listed". We conduct robustness checks and find that our results are not affected by changes in the tax regime.

In the next section we describe how the sample was constructed, and present descriptive statistics of the data. 


\section{The sample and descriptive statistics}

The Main Market in London is long-established, with roots that can be traced back to the $17^{\text {th }}$ century. While AIM is a much more recent phenomenon (launched in June 1995), the concept behind it is not new: the LSE previously created a market segment for smaller companies, called the Unlisted Securities Market (USM), which was only modestly successful. When AIM was launched, companies that were on the USM were given the option of switching onto AIM, which many of them took. ${ }^{14}$

The growth of AIM can be seen in Table 2, which shows the number of new admissions (including IPOs and switches from the MM), the number of overseas companies joining AIM and the trends in terms of money raised. As can be seen, the number of companies on AIM grew steadily until 1999, at which point the growth accelerated. From 347 companies trading on the market in 1999, the number at the end of 2007 stood at 1,694. Of course, the market valuation of the MM companies still swamps that of AIM, which attracts mainly small, growing companies. But the economic significance of AIM as a source of capital has increased over time, with over $£ 16$ billion being raised by AIM companies in 2007. Furthermore, the growth of international companies choosing AIM in recent years has been very impressive: 392 new overseas companies joined the market from 2004-2007.

To construct our sample of companies that switched from the MM to AIM and vice versa, we use data from the LSE, which classifies all AIM admissions. Between June 1995 and the end of 2006, 267 companies switched down to AIM and 73 switched up to the MM. We only consider switches that happened before 2007 to allow sufficient post-switch data for the analysis in section 4. Of the down switchers, we excluded one investment trust, and five companies whose primary listing was not in London. We then searched on Datastream for information on the remaining companies and could find data for all except five. This resulted in a base sample of 256 companies that moved down to AIM. Complete information could be obtained for all 73 companies switching up to the MM.

\footnotetext{
${ }^{14}$ This can be seen from Table 2, where the 123 new admissions to AIM in 1995 raised only £70m. This is because most of the companies who joined AIM in 1995 were switching from the USM, rather than conducting an IPO.
} 
While the date of the actual switch is recorded in the LSE database, typically, the management of the firm announces the intention to switch a few weeks prior to the switch. To find this announcement date for each company, we searched for up to a year prior to the switch date on Factiva, a database which encompasses newspapers, newswires, and the Regulatory News Service (RNS) provided by the London Stock Exchange. As noted earlier, during our sample period managers were not required to seek approval from shareholders to switch market segments. For down switchers, provided the company has the support of its nominated advisor, AIM admission is assured. For switching up to the MM, the approval of the UKLA is required, although normally the company would not announce a switch without first having checked that they satisfied the UKLA requirements. Consequently, although the typical announcement is expressed in terms of a future intention to switch market segments (such as "the company intends to transfer its listing to AIM" or "the company will be seeking admission to AIM" or "the board has resolved to transfer to the Main Market”), in effect these are more or less equivalent to announcing a firm decision to switch markets. As a potentially price-sensitive decision, the switching announcement should occur on the RNS first and this is indeed what we find. This results in a very precise definition of the announcement event, with very few cases of prior leakage of news. ${ }^{15}$

The news searches were also used to check whether any concurrent news or events occurred at the same time as the decision to switch markets was first announced. In most cases, the announcement to switch is accompanied by a short statement rationalising the decision. Most point to the lower costs (both financial and "continuing obligations"); many companies claim that AIM is a more appropriate market for a company of their size ("greater likelihood of attracting longer-term investor support"); and some companies point to the lower cost of future corporate transactions (as AIM does not charge for subsequent issues). However, there are some concurrent announcements that are highly significant to the company's valuation, and are likely to swamp any effect of the switch. In general, we employ the filter that if transactions require shareholder approval, they are excluded from the sample. For instance, in some cases

\footnotetext{
15 There are two companies where the announcement was made at a shareholder meeting and was subsequently reported to the RNS the next day and four days later, respectively. We use the earlier announcement date in both cases.
} 
there was an announcement of a major acquisition or disposal that would transform the overall composition of the company. Furthermore, in some cases the announcement of the market switch occurred when a major transaction was in process. In such cases, the shares were suspended at the time of the first announcement, and we exclude these firms from our sample as well. Collectively, these filters have the effect of excluding a variety of companies who announced their market switch at the same time as (or during) major transactions such as reverse takeovers, significant changes in corporate control (including takeovers, or issuance of options that, if exercised, would influence control), the sale of a main businesses, or where a company was, or became, a cash shell. Of those companies switching to AIM, 38 companies are excluded; and from those switching to the MM 17 are excluded. This leaves us with a sample of 218 (56) companies switching down (up).

There are other instances of companies making more minor concurrent announcements. These concurrent announcements fall into four main categories (a) the announcement of financial or trading results, (b) share issues or capital restructurings, (c) acquisitions and disposals, and (d) violations of one or more of the listing rules. The most frequently observed concurrent announcements relate to updates on trading or financial performance. In most cases these were routine updates, rather than announcements of major deteriorations or improvements in performance. The other two categories of concurrent announcements (share issues and capital restructurings; acquisitions and disposals) are rather more varied within the sample. In many cases, these transactions were rather minor in nature: for instance, the announcement of the disposal of a relatively small asset or business, or the issuance of new equity in relation to a new stock option plan. As mentioned earlier, the final category of concurrent announcements is very infrequently observed. For such listed (MM) firms, the decision to switch to AIM was forced onto the company as a result of a prior or anticipated violation of the listing rules (typically the violation related to the requirement for $25 \%$ of the company's shares to be in public hands).${ }^{16}$ We leave firms with any of these types of concurrent announcements in the sample to have a more representative set of switching

\footnotetext{
16 These changes are mostly involuntary, but there is at least one case where the violation of the rule - via the exercise of an option by a large shareholder/executive - was a deliberate strategy to require the company to move from the Main Market, possibly against the will of the other executives.
} 
firms. We do check the robustness of our results to dropping these firms from the sample, and find that the results are qualitatively unaffected by this change (indeed, the magnitudes of the return movements are not greatly affected when we drop these firms).

The flow of the switchers can be seen in Figure 1, along with the evolution of the market indices. This shows an interesting pattern: in the early days of AIM the switches tended to be "up" to the MM, whereas from the end of 2000 onwards the flow has been very strongly in the opposite "down" direction. The graph does not suggest any obvious relationship between the relative performance of the two market segments and the gross, or net, flows of companies.

Summary statistics for these market-switching companies are presented in Table 3. The market capitalisation of firms at the point they switched to AIM varies a great deal. The largest company had a market value in excess of $£ 500 \mathrm{~m}$, and a few such large companies result in the average market capitalisation of $£ 21 \mathrm{~m}$ being considerably above the median of $£ 8.6 \mathrm{~m}$. As noted above, there is no ongoing market capitalisation requirement for the $\mathrm{MM}$, and so none of these companies were required to transfer to AIM. ${ }^{17}$

Table 3 also shows that the median announcement date for the companies occurs 32 days prior to the switch to AIM occurring. There are also a few companies in the sample who made the first announcement several months before the actual switch, resulting in a mean lag between announcement and switch of 42 days. In the case of those switching up to the MM the gap between announcement and switching is slightly longer, on average 62 days with a median of 44 days. Half the companies simultaneously announced financial results, thus a smaller proportion (38\%) of the announcements were purely about the intention to switch. Not surprisingly, the average size of those companies switching up is larger than those switching down: median (mean) market capitalisation for the up switchers is around $£ 103 m(£ 175 m)$.

${ }^{17}$ In contrast, the analysis of Angel et. al. (2004) considers only those firms who violated one or more of NASDAQ's listing requirements. In their sample, the mean (median) market capitalisation of firms at the point of delisting was considerably smaller, at \$12.7m (\$4.4m) respectively. 
Finally, Table 3 includes information on the percentage of firms making other concurrent announcements when announcing their intention to switch to AIM. As noted earlier, it is quite common for companies to provide updates on their trading when they announce the switch to AIM; this occurred in $32 \%$ of our sample. Announcements of actual or potential listing rule violations are rare: these occur in only $2 \%$ of the firms in our sample. Announcements regarding minor transactions are somewhat more common: $12 \%$ of the companies also announce small share issues or other capital restructurings, and $7 \%$ announce actual, or intended, acquisitions or disposals. 52\% of companies made no other simultaneous announcements.

In the next section we analyse the immediate impact on share prices of the announcement to switch markets. Then, in section 5, we study the longer-term consequences for the financial performance of the companies.

\section{How do markets react when companies announce market switches?}

Investors' views regarding a company's market-switch announcement should, to a large extent, be captured in the short-term price movement around the announcement date. In this section we focus on the announcement event, and use the standard event-study methodology pioneered by Fama, Fisher, Jensen and Roll (1969). Of course, there is a second event - the actual switch date - and we present evidence in the next section on the share price performance of the companies after they actually switch.

Using the announcement dates, we line stocks up in event time, and analyze their abnormal returns over a 26-week window surrounding the event. We divide up this event window into three blocks of weeks prior to, during and after the event week: $[-13,-2],[-1,0,+1]$ and $[+2,+13]$. At this stage we employ a data-availability filter: any companies with missing observations during the estimation window were eliminated. This results in eight very thinly traded companies being excluded from each of the down and up switchers samples, thereby reducing the final sample used in the remainder of the paper from 218 to 210 companies switching down, and from 56 to 48 companies switching up.

Table 4 presents the raw returns, the returns of the broad market index, and risk-adjusted returns using a four-factor model. Panels A and B show these results for the down and up switchers respectively. 
Starting with the raw returns, down-switchers experience, on average, a modest (statistically insignificant) positive cumulative return in the 12-week periods prior to, and after, the announcement period, somewhat underperforming the FTSE All-Share index in each period. However, in the three-week period around the actual announcement (that is, $[-1,0,1]$ ) the mean cumulative return is $-5.4 \%$, which is statistically significant, whereas average market returns were close to zero. This initial evidence suggests that investors react negatively to the announcement that a company intends to switch, although it is clearly necessary to check the robustness of this result within a more sophisticated abnormal return model, to which we return below.

Panel B reveals a reverse pattern in terms of the raw returns experienced by those companies switching up. These stocks perform strongly in the three months prior to announcing their switch from AIM to the Main market, with a mean cumulative return of $4 \%$. They experience a further $5.4 \%$ boost in the three weeks surrounding the announcement of the switch. The positive returns continue over the subsequent twelve weeks, where the average CAR is 9.8\%. Although these are large effects, given the relatively small sample sizes, the statistical significance is limited: the event returns and the post-event returns are significant at the $10 \%$ confidence level. The movements in the market were, on average, modestly positive before, during and after the event window. To go further, we must risk adjust, and compute cumulative abnormal returns, to see if these patterns persist once these factors have been accounted for.

We construct the abnormal returns in two steps. First, we estimate event parameters over an estimation window using a factor model. We employ Carhart's (1997) four factor model, using the FTSE All-Share index as our proxy for the market, and SMB, HML and Momentum (UMD) factors constructed using all FTSE All-Share index constituents over the sample period. ${ }^{18}$ We regress each firm's stock returns on the four factors in a 52-week estimation window prior to the event window, that is, [-78,-27].

\footnotetext{
${ }^{18}$ We have also employed a range of alternative factor models, including simple market adjustment using both the FTSE All-Share and the AIM indices, a one-factor market model, and a two-factor model using both the FTSE AllShare index and the AIM index. Our results are qualitatively unaffected by these different methods of risk adjustment - the graphical representation of our results in Figure 2 includes these alternative CARs.
} 
We employ the Dimson (1979) correction in our regressions, to mitigate potential biases arising from nonsynchronous trading. Writing $r_{i, t}$ for the returns of firm $i$ at date $t$ in the estimation window, we estimate:

$$
r_{i, t}=\alpha_{i}+\sum_{k=-1}^{k=1}\left(\beta_{i, F T S E}^{k} r_{F T S E, t+k}+\beta_{i, S M B}^{k} r_{S M B, t+k}+\beta_{i, H M L}^{k} r_{H M L, t+k}+\beta_{i, U M D} r_{U M D, t+k}\right)+\varepsilon_{i, t}
$$

$$
\begin{aligned}
& \hat{\beta}_{i, \text { FTSEDIM }}=\hat{\beta}_{i, \text { TSSE}}^{-1}+\hat{\beta}_{i, \text { TSSE }}^{0}+\hat{\beta}_{i, \text { TTSE }}^{+1} \\
& \hat{\beta}_{i, \text { SMBDIM }}=\hat{\beta}_{i, \text { SMB }}^{-1}+\hat{\beta}_{i, \text { SMB }}^{0}+\hat{\beta}_{i, \text { SMB }}^{+1} \\
& \hat{\beta}_{i, \text { HMLDIM }}=\hat{\beta}_{i, H M L}^{-1}+\hat{\beta}_{i, H M L}^{0}+\hat{\beta}_{i, H M L}^{+1} \\
& \hat{\beta}_{i, \text { UMDDIM }}=\hat{\beta}_{i, \text { UMD }}^{-1}+\hat{\beta}_{i, \text { UMD }}^{0}+\hat{\beta}_{i, \text { UMD }}^{+1}
\end{aligned}
$$

Table 5 shows summary statistics of these estimated parameters (we focus in this section on the parameters for the announcement event; in the next section we use the parameters estimated relative to the actual switch). On average, down switchers have positive loadings on SMB and a negative loading on HML, reflecting the fact that the returns of these firms co-move with those of small growth firms (there are a number of internet/computer software companies in the sample, although the sample is fairly balanced between old and new economy firms). Up switchers also have positive loadings on SMB, and strongly positive loadings on UMD, reflecting their strong momentum in the year prior to the event window.

To create abnormal returns, we subtract the estimated fitted value from realized firm returns for dates $t$ in the event window:

$$
r_{i, t}^{a b n o r m a l}=r_{i, t}-\hat{\beta}_{i, F T S D I M} r_{F T S E, t}-\hat{\beta}_{i, S M B D I M} r_{S M B, t}-\hat{\beta}_{i, H M L D I M} r_{H M L, t}-\hat{\beta}_{i, \text { UMDDIM }} r_{U M D, t}
$$

Note that we do not subtract off the estimated $\hat{\alpha}_{i}$ for each firm, i.e., we set it to zero when computing abnormal returns. We do so since are interested in abnormal returns relative to factor loadings, rather than abnormal returns relative to past outperformance by the firm. ${ }^{19}$

\footnotetext{
${ }^{19}$ The estimates of $\hat{\alpha}_{i}$ for the up switchers, tend to be large, reflecting strong pre-announcement performance by these firms. Thus, abnormal returns in the event window, especially for the up-switchers, tend to be quite negative when these estimates are incorporated, by construction. Our results for the down switchers are unaffected by the inclusion of these estimated intercepts when constructing abnormal returns. All of these results are available on request.
} 
We then sum computed abnormal returns over the event window, to create cumulative abnormal returns (CARs). These CARs are a measure of abnormal price increases. We then test whether the CARs are statistically different from zero around the announcement and switch dates. In order to do this, we employ the nonparametric delete-cross-section jackknife estimator, in the spirit of Shao and Wu (1989) and Shao (1989). ${ }^{20}$ The jackknife does not require normality, is consistent in the presence of heteroskedasticity and cross-correlation of firm returns in event time. This is equivalent to clustering all firm residuals in each event time period.

Table 4 presents the CARs for the switching firms estimated in the 26 weeks around the event. Panel A reveals that on average, relative to the four factor model, the firms that switched down experienced a CAR of around $-4.3 \%$ in the three weeks surrounding their announcement of a move from the Main Market to AIM. Panel B shows the corresponding results for firms that switched in the opposite direction, up to the MM from the AIM market. The up switchers have positive CARs in the weeks before and immediately after the announcement. These point estimates are, however, not statistically significant using the jackknife standard errors. In the 12 weeks after the announcement, average CARs are $+2.2 \%$ for the down switchers and $+9.9 \%$ for the up switchers, the latter being statistically significant. A visual representation of these results is presented in Figure 2 (which also shows the results using the three alternative risk-adjustment techniques).

In general, the switch between markets that we focus on in this paper is a very clean form of event-study, where the main change is in the nature of regulation. However, we encountered two complications - contemporaneous announcements and changes in the tax regime - which could impact on the results. Consequently, we performed some robustness checks. First, as noted in section 2, the announcement that the firm is going to switch markets is often accompanied by other news, such as

\footnotetext{
${ }^{20}$ To compute the jackknife standard error for an estimator, we form the estimator for $T$ delete-cross-section jackknife data samples, constructed by deleting all stocks $i$ for each event time period $t$ in $T$. The standard deviation of the resulting jackknife trials, appropriately scaled, is the jackknife standard error of the estimator. For comparison purposes, we also computed standard errors using the White heteroskedasticity-consistent estimator. The results are qualitatively similar, but far more statistically significant using the White estimator, as might be expected.
} 
updates on operating performance or minor corporate transactions. We excluded $a b$ initio any companies for which the concurrent announcements were judged to be significant, and so might contaminate our analysis. However, the results reported to date include those companies that made other more minor announcements at the same time that they announced their intention to switch market. As a robustness check, we re-ran the analysis having removed the 38 (7) firms from the down (up) switching sample that made such simultaneous announcements. The results are almost identical when these firms are excluded from the sample. Similarly, if we re-estimate the event study separately in the three slightly different tax regimes that existed in our sample period, the results are largely unchanged (although sample sizes start to become an issue). These results are available on request.

In summary, the announcement of a switch down to AIM results in an average raw return of 5.4\% and CARs of around $-4.3 \%$. These negative returns square with the intuition that the switch conveys negative information about the firm - in terms of the impact of weaker future corporate governance on switching firms. However, these results also raise the question as to why management decided to switch market segments in the first place, if it really was against shareholders' interests. The results we obtain for the up switchers are remarkably similar in the opposite direction - raw average returns of $+5.4 \%$ and CARs of $+4.6 \%$, although these should be interpreted with care given the much smaller sample size. We find that companies tend to switch up after strong performance, whereas the average performance of down switchers is broadly in line with the market. In the next section we explore the longer-term impact of switching markets by investigating, in particular, whether the changes in regulatory standards have any discernible impact on firm performance.

\section{How do firms perform after they switch markets?}

In principle it would be expected that any impact of changing regulatory regimes would be capitalized into share prices around the announcement day. However, as well as these immediate announcement effects, we are interested in whether switching markets and regulatory regimes impacts on company performance, and, if so, whether or not these effects were fully anticipated and capitalized into the share price responses 
at the announcement. To investigate this we start by analysing the longer-term share price performance and then consider how the operating performance of the companies changes after the switch.

\subsection{Longer-term share price performance}

We analyse in this section the share price performance of companies after they actually switched markets, and in particular whether we observe any systematic excess returns. We use the same risk-adjustment methodology as in the previous section, and analyse returns in the year after the switch. Table 6 presents the results. Most strikingly, we find strong positive drift for the down-switchers in the year following the switch. Quarterly raw returns are strongly positive, especially in the first two quarters after the switch, where raw average returns of $+8.3 \%$ and $+7.0 \%$ are found. Over the first year after switching, raw cumulative returns average around $+20 \%$.

These surprising results remain when we risk-adjust the returns. The risk-adjustment parameters for our four-factor model are presented in Table 5, where the switch date is set as week 0. Average CARs in the year after the companies switch from the Main Market to the less-regulated AIM market are around 25\% using our four-factor model. This post-switch drift can be seen clearly in Figure 3, where CARs using alternative risk-adjustment techniques (using either or both of AIM and the MM as factors) are shown. These simpler models suggest somewhat lower average CARs - in the range of $13-18 \%$ over the first year - but in all cases we can easily reject the null hypothesis that post-switch performance is, on average, in line with the market.

In contrast, the average performance of the companies switching up from AIM to the MM shows no such drift. In no quarter during the year following the switch are either the raw returns or the CARs significantly different from zero. The raw returns over the year post-switch are mildly positive at $+2.9 \%$, which is somewhat below the market return. The development of the CARs can be seen in Panel B of Figure 3: depending on the factor model employed, the cumulative CARs at the end of the first year range from about $-10 \%$ to $+3 \%$, and in no case are the cumulative returns significantly different from zero. However, it should be recalled that our sample of up-switchers is small relative to the down-switchers. 
This post-switch upward drift associated with companies switching to AIM is intriguing and warrants further investigation. One possible explanation is that the drift is largely technical, resulting from the impact of index inclusion effects. We investigate this in the next section, before turning to an alternative explanation - namely whether ownership changes occur around the switch that might influence observed returns.

\subsection{Does index inclusion explain the post-switch drift?}

One possible explanation for the pattern of returns that we observe is the impact of the firms being deleted from or added into share price indices. These effects have been well-documented in the literature (see Shleifer (1986) and Harris and Gurel (1986)). This is potentially relevant to this study, as when a company ceases to be on the Main Market it is no longer eligible for certain indices (such as the FTSE All Share index), although once it switches to AIM it becomes eligible for alternative indices (such as the FTSE AIM index). However, while the removal from an index is immediate once the eligibility criteria are no longer satisfied, new candidates for index inclusion are only considered periodically (typically every three months). Therefore, for example, when a company announces its intention to switch from the MM to AIM, the shares may be discounted in anticipation of the index removal at the point of the switch. However, any subsequent inclusion in the indices post-switch will depend on the date of the switch relative to the revision cycle for index composition. Hence, when the entire portfolio of switchers is analysed in event time, the likely positive impact of index inclusion will be averaged out over several months, which may explain the steady upward drift in returns.

To test this hypothesis we determined the dates when index changes were made for the companies in our sample. The indices we consider are the FTSE AIM, FTSE Fledgling, FTSE Small Cap, FTSE All Share, FTSE 250 and the Hoare-Govett Small Companies. Together, these indices constitute the major small company indices in the UK market. We then set the returns in the three-week period surrounding any index inclusion or deletion event to zero and re-estimate the CARs. This results in 612 (573) firm weeks being excluded in respect of index deletions (inclusions). The results are presented in Table 7, where event time is measured relative to the switch date. For both up- and down-switchers the 
results are similar to those presented in Table 6: for down-switchers the post-switch CARs grow to around $+25 \%$ in the year after the switch, and for the up-switchers the average CARs are negative at around $-11 \%$ (and still lack statistical significance). This suggests either that the effects documented in the literature are swamped by other effects of switching market segments, or that index inclusions and deletions are not as important for small companies as they are, for example, for companies entering and leaving the S\&P 500 . Either way, the pattern of post-switch CARs we observe are not explained by index inclusion and deletion effects. $^{21}$

\subsection{Does ownership change when firms switch markets?}

An alternative hypothesis we explore is whether the pattern of returns we observe could be influenced by significant changes in ownership around the switch date. For instance, if the announcement of the intention to switch caused some significant investors to sell, or buy (if, for example, institutional investors are restricted in their mandates to holding "listed" shares), this could have a price impact as positions were sold or bought. This could be especially important in this study since, as noted earlier, most of the companies have a relatively modest market capitalisation, and average annual turnover in the down (up) sample is $48 \%$ (59\%) per week in the year prior to the announcement to switch markets. ${ }^{22}$ Consequently, if an investor wanted to sell or buy a sizeable position, this might take several weeks to execute, possibly generating the observed pattern of returns.

To investigate this hypothesis we obtained detailed information on the significant ownership stakes of a sub-set of our companies. ${ }^{23}$ In the U.K. stakes above $3 \%$ have to be declared, as do the

\footnotetext{
${ }^{21}$ Note that the post-switch Q4 results are identical in Tables 6 and 7; this is because there are no index inclusion/deletion events identified for the sample firms in this quarter.

${ }^{22}$ For comparison, the average annual turnover for the smallest size quintile of stocks on the NYSE is $55 \%$ over the 1993-2000 period (see Campbell, Ramadorai and Schwartz (2008)).

${ }^{23}$ We are extremely grateful to Tehmina Khan for making this data available to us. Because of some limitations in the coverage of firms, the Hemscott data upon which we rely was only available for 119 of the down-switchers and 32 of the up-switchers.
} 
shareholdings (of any magnitude) of directors. Any changes in such stakes have to be reported immediately, and so we are able to track changes in ownership very accurately in event time.

Figure 4 shows that the aggregate ownership proportions of major shareholders and directors around market switches are remarkably stable. For both up- and down-switchers, the directors of the firm hold about $15 \%$ of the equity in aggregate, and there is, if anything, a modest increase in this aggregate holding for down-switchers in the weeks before the actual switch, and a similarly modest reduction in holdings in the case of up-switchers. Thereafter, directors' holdings change very little in aggregate. In the case of outside major shareholders, aggregate holdings are very stable in the period before the switch, and there appears to be little systematic selling or buying between the announcement date and the actual switch. ${ }^{24}$

The one interesting trend is that for down-switchers there is a small increase in aggregate institutional holdings in the six months following the switch to AIM, from $23 \%$ to nearly $25 \%$. While such an increase could not explain the upward drift in returns post-switch, it suggests that institutional investors are not abandoning companies once they switch to lower-regulation markets. Overall, this evidence on ownership changes around the market switch is striking more for the stability in the shareholdings of significant investors, than for any changes in their positions over the period following the switch, and so does not provide an explanation in itself for the pattern of returns.

The final hypothesis we investigate is whether the switch between markets affected the operating performance of firms. At least for those switching down to AIM, one of the main reasons for switching given by management - as reflected in some of the quotations reported earlier - was that it would cut the direct and indirect costs of the regulatory regime and increase flexibility. For those switching up to the MM, such arguments would tend to operate in reverse. Of course, any such post-switch changes in performance will only influence equity returns to the extent that they were not fully anticipated at the time of the announcement. We investigate this question in detail later in the paper.

\footnotetext{
${ }^{24}$ The figures we report are aggregated across all investors holding more than $3 \%$ stakes, but the stability in the aggregate reflects few changes in the underlying individual holdings, rather than significant selling and buying activity that nets out.
} 


\subsection{What happens to operating performance after switching markets?}

To measure operating performance we gather accounting data from the switching companies' annual accounts. There are many different measures of performance, but we focus on earnings before interest, taxation, depreciation and amortization (EBITDA). ${ }^{25}$ EBITDA is a good proxy for cash-flow (provided depreciation and capital expenditures are roughly equal) and tends to be reasonably comparable over time. We normalize EBITDA by the book value of total assets in order to obtain a measure of the rate of return. This information can be obtained for most, but not all, of the companies in our sample, and in Table 8 we report the results for the five years around the switch. Note that since we are relying here on data from annual accounts, the timing of the accounting years and event time will vary across companies, but in all cases we follow the convention that the reported figures derive from the last published accounts prior to the event year. Thus year zero is the last complete fiscal year prior to the fiscal year in which the firm switched markets.

Starting with the down-switchers we see that total assets remained, on average, remarkably constant over the 5-year period around the switch. However, the pattern of EBITDA is intriguing, falling significantly between years -2 and 0 and then rising sharply after the switch. This results in a noticeable pattern in our measure of the rate of return, which we show graphically in Figure 5. On an asset-weighted basis, EBITDA/Total Assets averaged only $1.4 \%$ in the last accounts published before the switch to AIM, but had recovered to $8.8 \%$ two years later. A similar pattern is observed in the unweighted average return, which increases from $0.4 \%$ to $5.4 \%$. There are clearly many other ways to measure operating performance, but this evidence suggests that, on average, financial performance improves significantly after the switch to AIM.

The operating performance of the up-switchers is quite different. These companies exhibit, on average, strong and consistent growth in total assets, from $£ 32 \mathrm{~m}$ two years before the switch to $£ 177 \mathrm{~m}$ two years after the switch. EBITDA grows over the period, but dips noticeably in year 0. The resultant

\footnotetext{
${ }^{25}$ We prefer this measure to reported measures of profitability, which can be influenced by all sorts of provisions, non-cash items or accounting conventions on amortization.
} 
rates of return show no obvious patterns. The main conclusion we draw from this sample is that firms that switch up to the MM do so in anticipation of a significant increase in the scale of their activities.

Returning to the companies switching down to AIM, an interesting question is to what extent the observed pattern of operating improvements explains the steady upward drift in CARs post-switch. While we observe annual snapshots of operating performance from the accounts, our evidence on returns stretches out a year after the switch. This period should, for most companies, encompass the publication of the first post-switch set of annual accounts. But presumably investors will have received higher frequency information from trading updates and equity analysts, which may have changed expectations of future performance well before the formal results were published. Of course, investors' valuations may depend on many other performance measures, and we have only presented evidence on one such measure. But one way to investigate whether the two phenomena of improved operating performance and post-switch positive drift in returns are linked is to see whether they are related cross-sectionally.

We do this in Table 9 by analysing whether the post-switch returns over the year after the switch forecast future operating performance. If operating performance had been anticipated at the time of the announcement we would expect the share price to have jumped at that point - and forecast the future operating performance - and that the post-switch returns should have no forecasting power. Since any impact of switching markets on operating performance might take some time to materialise, we focus on the return on assets (ROA) in period +2 , and include the four previous years' ROA to allow for persistence in accounting returns. We also control for possible firm size effects (using the log of market capitalisation) and firm growth factors (using book-to-market ratios). We include CARs in the announcement week, over the first year post-switch, and also in the quarter prior to the announcement (in case the market had anticipated the announcement). We estimate cross-sectional regressions using both an OLS and a Weighted Least Squares (WLS) estimator, where the weights are the square root of market 
capitalisation. ${ }^{26}$ Since the WLS estimator controls for the impact of size, market capitalisation is not included as a control in these regressions.

Starting with the down switchers, the results show that cross-sectional operating performance, as captured by our measure of the return on assets, is persistent over time, with positive coefficients on each of the lagged dependent variables. We find no relationship between firm size or book/market ratio on future performance. Turning to the extent to which the previous share price performance can forecast future operating performance, we find the announcement week CAR has explanatory power. This is interesting, since if investors could anticipate the impact of switching to AIM on performance, and the announcement was a surprise, the main impact should be capitalised into the share price around the announcement date. However, the most interesting result is that the CAR in the year following the switch does forecast operating performance in the cross-section. This is consistent with the interpretation that investors did not fully anticipate the impact of switching markets on operating performance at the time of the announcement, and that as new information was produced over the first year, share prices responded accordingly. Unfortunately, we are unable to estimate this cross-sectional regression for the up switchers, since the small sample size and the necessarily large number of regressors results in very low degrees of freedom for this set of firms.

In summary, in this section we first analysed the post-switch returns and found economically (and statistically) significant positive returns in the year after firms switched from the Main Market to the less regulated AIM. We find modest, but insignificant, negative returns for those switching in the opposite direction. We then explored some possible explanations for the observed post-switch performance, in particular for the down-switchers. We find that the results are not driven by index inclusion/deletion effects, nor are they driven by changes in the stakes held by large shareholders. However, we do find that operating performance for the down-switchers improves significantly in the two years post-switch, and that the observed positive drift has forecasting power for future operating returns. These results suggest

\footnotetext{
${ }^{26}$ Our use of WLS with market capitalization weights is motivated by the sense that the accounting data reported by smaller firms is less precise than that reported by larger firms.
} 
that the switch to a less regulated environment can be beneficial to some companies. However, our results indicate that investors do not fully anticipate these potentially positive consequences of the switch. Our interpretation of the post-switch drift is that over time, investors gradually revise their expectations regarding operating performance and firm valuation in the months after the switch as new information becomes available.

Clearly, if such performance improvements became widely understood and predictable, we would expect the pattern of returns to flatten out and eventually be captured on the announcement date. As far as we are aware, however, our paper is the first to analyse the share price and operating performance of companies that switch between the London markets.

\section{Discussion and conclusions}

In this paper we examine the consequences of switching between markets with different regulatory standards. To address this question, we exploit the unique environment that exists in London, where there are two markets with different levels of regulation that use identical trading technology. London has seen a large number of companies that have chosen to switch between the Main Market and AIM, which provides us with an excellent test-bed for analysing the impact of high versus low levels of regulation on firm value. We also present evidence on the operating performance post-switch. Our analysis is highly pertinent to current debates in the U.S. and E.U. regarding the appropriate extent of regulation given the observed flight of many companies away from highly-regulated markets, and may also help to provide an explanation for the impressive growth of AIM in recent years.

We find significant announcement effects associated with the decision to switch market. Companies move from AIM to the Main Market, in general, following periods of strong performance, and when they announce the switch, they experience a positive return of around $5 \%$. In the year after the switch returns are broadly neutral, although some forms of risk-adjustment generate mildly negative returns. The operating performance, as measured by return on assets, of these companies shows no clear trend in the five years around the switch date, although the firms grow their assets significantly. 
The more interesting results relate to the much larger sample of companies that switch down to AIM. We observe negative announcement effects - on average around -5\% - that are broadly the opposite of those switching to the Main Market. There is clear evidence, therefore, that the initial response of investors to the news of a switch is negative. Intriguingly, however, this is not the end of the story. We demonstrate that there is a prolonged and significant positive drift in the share prices once the companies start trading on AIM. Using a four-factor model, the estimated average CARs approach $+25 \%$ one year after the switch. The net result for investors is, therefore, positive.

We investigate whether this pattern of results is driven by index inclusions and exclusions over the event period, or to the sale and/or purchase of large blocks of shares by insiders and institutional investors, and conclude that the evidence supports neither hypothesis. On the other hand when we investigate the actual operating performance of the switching companies, we find significant improvements in performance in the two years following the switch down to AIM. The steady increase in CARs in the post-switch period for those switching to the less-regulated environment of AIM is certainly consistent with the hypothesis that investors gradually learn about this improved operating performance and share prices respond accordingly. Given that the performance improvement that we report occurs over the two-year period following the switch, it is not entirely surprising that it was not fully anticipated at the switch date. However, should such improvements become anticipated as the norm, then the announcement effect might well reverse and become positive.

Overall, our results suggest that the most suitable regulatory regime may differ across companies. In the case of smaller quoted companies - of the sort that we focus on in this paper - the dominant flow in the UK in the last decade has been away from the Main Market to the more lightly regulated AIM. Our results suggest that the management of the companies that switched to AIM were not, in general, acting against the interests of their shareholders, notwithstanding the initial negative announcement effect. The operating performance of the companies within the less-regulated environment was, on average, significantly improved and within a few months of the switch the share prices had more than recovered. Such results suggest that the less regulated market segments that have been created in many countries may well flourish. 


\section{References}

Angel, J.J., Harris, J.H., Panchapagesan, V. and Werner, I.M., 2004. From Pink Slips to Pink Sheets: Liquidity and Shareholder Wealth Consequences of Nasdaq Delistings, Working Paper.

Benston, G.J., 1973. Required Disclosure and the Stock Market: An Evaluation of the Securities Exchange Act of 1934. American Economic Review 63, 132-155

Bushee, B., and Leuz, C., 2005. Economic Consequences of SEC Disclosure Regulation: Evidence from the OTC Bulletin Board. Journal of Accounting and Economics 29, 233-264.

Campbell, John Y., Ramadorai, T. and Schwartz, A. 2008. Caught on tape: Institutional trading, stock returns and earnings announcements. Journal of Financial Economics, forthcoming.

Carhart, Mark. 1997. On Persistence in Mutual Fund Performance, Journal of Finance, 52, 57-82.

Coates, J., 2007. The Goals and Promise of the Sarbanes-Oxley Act. Journal of Economic Perspectives 21, 91-116.

Dimson, E., 1979. Risk Measurement when Shares are Subject to Infrequent Trading. Journal of Financial Economics 7, 197-226.

Doidge, C., Karolyi, G.A., and Stulz, R.M, 2007. Has New York Become Less Competitive in Global Markets? Evaluating Foreign Listing Choices over Time. ECGI Finance Working Paper.

Easley, D.A., T. Hendershott and Ramadorai, T., 2008. The Price of Latency. Unpublished working paper.

Fama, E., Fisher, L., Jensen, M., and Roll, R., 1969. The Adjustment of Stock Prices to New Information. International Economic Review 10, 1-21.

Ferrell, A., 2004. Mandated Disclosure and Stock Returns: Evidence from the Over-the-Counter Market. Harvard Law School.

Greenstone, M., Oyer, P., and Vissing-Jorgensen, A., 2006. Mandated Disclosure, Stock Returns, and the 1964 Securities Act Amendments. Quarterly Journal of Economics 1221, 399-460.

Harris, L., and Gurel, E. 1986. Price and volume effects associated with changes in the S\&P 500: New evidence for the existence of price pressures. Journal of Finance 41, 815-829.

Iliev, P., 2007. The Effect of the Sarbanes-Oxley (Section 404). Working Paper, Brown University. 
Jain, P.K., 2005. Financial Market Design and the Equity Premium: Electronic vs. Floor Trading. Journal of Finance 60, 6, 2955-2985.

Karolyi, G.A., 2006. The World of Cross-Listings and Cross-Listings of the World: Challenging Conventional Wisdom. Review of Finance 10, 99-152.

Leuz, C., 2007. Was the Sarbanes-Oxley Act of 2002 Really this Costly? A Discussion of Evidence from Event Returns and Going Private Decisions. Journal of Accounting and Economics 44, 146-55.

Leuz, C. and Wysocki, P., 2008. Economic Consequences of Financial Reporting and Disclosure Regulation: A Review and Suggestions for Future Research. Working paper, University of Chicago.

Macey, J., and O’Hara, M., 2002. The Economics of Stock Exchange Listing Fees and Listing Requirements. Journal of Financial Intermediation, 11, 297-319.

Mahoney, P.G. and Mei, J., 2006. Mandatory Versus Contractual Disclosure in Securities Markets: Evidence from the 1930s. Working paper, University of Virginia Law School.

Shao, J. 1989. The Efficiency and Consistency of Approximations to the Jackknife Variance Estimators. Journal of the American Statistical Association 84, 114-119

Shao, J. and Wu, C. F.J, 1989. A General Theory for Jackknife Variance Estimation. Annals of Statistics $17,1176-1197$

Shleifer, A. 1986. Do demand curves for stocks slope down? Journal of Finance 41, 579-590.

Simon, C.J., 1989. The Effect of the 1933 Securities Act on Investor Information and the Performance of New Issues. American Economic Review 79, 295-318

Stigler, G.J., 1964. Public Regulation of the Securities Markets. Journal of Business 37, 117-142

Stulz, R.M., 1999, Globalization, Corporate Finance, and the Cost of Capital. Journal of Applied Corporate Finance 12, 8-25.

White, Halbert, 1980. A Heteroskedasticity-Consistent Covariance Matrix Estimator and a Direct Test for Heteroskedasticity. Econometrica 48, 817-838.

Zingales, L., 2006. Is the US Capital Market Losing its Competitive Edge? Working Paper, November. 
Table 1

\section{Comparison of the Main Market and the Alternative Investment Market}

\section{Admissions requirements}

Minimum 25\% shares in public hands

Normally 3 year trading record required

Pre-vetting of admission documents by the UKLA, or another recognised EU authority

Admission takes several months

Minimum market capitalisation on entry (£700K) No minimum market capitalisation

Nominated adviser required at all times

Sliding scale admission fees: e.g. £16K, £49K, $£ 142 \mathrm{~K}$ respectively for $£ 10 \mathrm{~m}, £ 100 \mathrm{~m}$ and $£ 1 \mathrm{bn}$ market cap at issue

Flat rate admission fee: $£ 4 \mathrm{~K}$
No minimum shares in public hands

No trading record requirement

Admission documents not pre-vetted by Exchange or any listing authority

Admission can be achieved within 2 weeks

\section{Continuing Obligations}

Prior shareholder approval required for substantial acquisitions and disposals

No prior shareholder approval for transactions

Sponsors needed for certain transactions

Companies are subject to extensive continuing

obligations as required by the UKLA

Sliding scale annual fees: e.g. £8K, £8K, £20K respectively for $£ 10 \mathrm{~m}, £ 100 \mathrm{~m}$ and $£ 1$ bn market capitalization stocks

Flat rate annual fee: $£ 4 \mathrm{~K}$

\section{Other Costs and Benefits}

Fees charged for subsequent issues

No charge for subsequent issues

Aim companies enjoy some tax benefits - since UK tax authorities treat most AIM companies as unquoted "business" assets 


\section{Table 2}

\section{The Growth of the AIM Market}

This table shows the development of the AIM market since its inception. Ten companies previously on the Unlisted Securities Market were transferred to AIM when it opened in June 1995. The first block of columns shows the total number of companies quoted at the year end; international companies are those from outside the UK. New admissions comprise IPOs and transfers from the Main Market. We do not report those companies that left the market - either due to takeovers, switches to the MM, or cancellations - although this flow can be inferred from the difference between the first two blocks of figures. Money raised is split into funds raised at the time of the IPO or on transfer from the Main Market (Initial Issues), and further issues by AIM quoted companies. Source: London Stock Exchange AIM market statistics, December 2008.

\begin{tabular}{lccccccc}
\hline Year & \multicolumn{2}{c}{ Quoted Companies } & \multicolumn{2}{c}{ New Admissions } & \multicolumn{3}{c}{ Capital Raised (Em) } \\
& Total & $\begin{array}{c}\text {..of which } \\
\text { International }\end{array}$ & Total & $\begin{array}{c}\text {. of which } \\
\text { International }\end{array}$ & Initial Issues & Further Issues & Total \\
\hline 1995 & 121 & 3 & 123 & 3 & 69.5 & 25.3 & 94.8 \\
1996 & 252 & 17 & 145 & 14 & 514.1 & 302.3 & 816.4 \\
1997 & 308 & 22 & 107 & 7 & 344.1 & 350.2 & 694.3 \\
1998 & 312 & 21 & 75 & 7 & 267.5 & 290.1 & 557.6 \\
1999 & 347 & 22 & 102 & 6 & 333.7 & 599.8 & 933.5 \\
2000 & 524 & 31 & 277 & 12 & $1,754.1$ & $1,319.7$ & $3,073.8$ \\
2001 & 629 & 42 & 177 & 15 & 593.1 & 535.3 & $1,128.4$ \\
2002 & 704 & 50 & 160 & 13 & 490.1 & 485.8 & 975.8 \\
2003 & 754 & 60 & 162 & 16 & $1,095.4$ & 999.7 & $2,095.2$ \\
2004 & 1021 & 116 & 355 & 61 & $2,775.9$ & $1,880.3$ & $4,656.1$ \\
2005 & 1,399 & 220 & 519 & 120 & $6,461.2$ & $2,481.2$ & $8,942.4$ \\
2006 & 1,634 & 304 & 462 & 124 & $9,943.8$ & $5,734.3$ & $15,678.1$ \\
2007 & 1,694 & 347 & 284 & 87 & $6,581.1$ & $9,602.8$ & $16,183.9$ \\
& & & & & & & \\
Total & & & $\mathbf{2 , 9 4 8}$ & $\mathbf{4 8 5}$ & $\mathbf{3 1 , 2 2 3 . 6}$ & $\mathbf{2 4 , 6 0 6 . 7}$ & $\mathbf{5 5 , 8 3 0 . 3}$ \\
\hline
\end{tabular}


Table 3

Characteristics of the Sample

This table shows the sample of companies that switched from the Main Market to AIM (top panel), and from AIM to the Main Market (bottom panel), between 1995 and the end of 2006. Companies that made major acquisitions or disposals - the impact of which would dominate the switch - have been excluded from the sample (see discussion in Section 2 for details). Companies are classified by year according to the date of the first public announcement of their intention to switch, rather than the date of the actual switch. Days preannounced refers to the gap between the first public announcement of the intention to switch market segments and the actual date of the switch. 'Also Announced' refers to items that were included in the regulatory news filing at the same time as the announcement of the intention to switch to AIM. As some companies made simultaneous announcements in more than one category these percentages do not add up to 100.

\begin{tabular}{|c|c|c|c|c|c|c|c|c|c|c|c|}
\hline Main Market-AIM & 1997 & 1998 & 1999 & 2000 & 2001 & 2002 & 2003 & 2004 & 2005 & 2006 & Total \\
\hline N(Firms) & 5 & 2 & 6 & 14 & 28 & 37 & 42 & 21 & 35 & 28 & 218 \\
\hline \multicolumn{12}{|l|}{ Days Pre-Announced } \\
\hline Mean & 32 & 22 & 30 & 35 & 48 & 35 & 42 & 52 & 57 & 67 & 42 \\
\hline Median & 17 & 22 & 30 & 33 & 32 & 31 & 33 & 32 & 53 & 61 & 32 \\
\hline \multicolumn{12}{|l|}{ Market Cap. on Transfer } \\
\hline Mean $(£ m)$ & 8.7 & 34.4 & 4.2 & 46.8 & 11.2 & 9.0 & 16.2 & 23.9 & 31.0 & 24.0 & 21.0 \\
\hline Median (£m) & 8.6 & 34.4 & 3.6 & 8.4 & 6.5 & 5.8 & 8.7 & 10.0 & 16.9 & 17.7 & 8.6 \\
\hline \multicolumn{12}{|c|}{ Also Announced (\% of sample) } \\
\hline Financial Results & & & & & & & & & & & $32 \%$ \\
\hline Listing Rule Violation & & & & & & & & & & & $2 \%$ \\
\hline Share Issue/Restructuring & & & & & & & & & & & $12 \%$ \\
\hline Minor Acquisition/Disposal & & & & & & & & & & & $7 \%$ \\
\hline No Announcement & & & & & & & & & & & $52 \%$ \\
\hline AIM-Main Market & 1997 & 1998 & 1999 & 2000 & 2001 & 2002 & 2003 & 2004 & 2005 & 2006 & Total \\
\hline N(Firms) & 0 & 16 & 10 & 10 & 6 & 4 & 3 & 2 & 2 & 3 & 56 \\
\hline \multicolumn{12}{|l|}{ Days Pre-Announced } \\
\hline Mean & 0 & 42 & 38 & 63 & 110 & 57 & 59 & 44 & 128 & 85 & 62 \\
\hline Median & 0 & 34 & 32 & 75 & 38 & 44 & 70 & 44 & 128 & 75 & 44 \\
\hline \multicolumn{12}{|l|}{ Market Cap. on Transfer } \\
\hline Mean (£m) & & 61.1 & 119.9 & 217.5 & 94.2 & 125.8 & 261.1 & 145.0 & 268.6 & 283.7 & 175.2 \\
\hline Median (£m) & & 42.5 & 46.5 & 101.6 & 107.8 & 123.3 & 163.4 & 145.0 & 268.6 & 274.2 & 102.9 \\
\hline \multicolumn{12}{|c|}{ Also Announced (\% of sample) } \\
\hline Financial Results & & & & & & & & & & & $50 \%$ \\
\hline Listing Rule Violation & & & & & & & & & & & $0 \%$ \\
\hline Share Issue/Restructuring & & & & & & & & & & & $11 \%$ \\
\hline Minor Acquisition/Disposal & & & & & & & & & & & $2 \%$ \\
\hline No Announcement & & & & & & & & & & & $38 \%$ \\
\hline
\end{tabular}




\section{Table 4}

\section{Announcement Returns}

This table presents returns around the announcement of a switch between market segments for the firms in our sample. Panel A shows the results for the Down switchers, comprising 210 firms which switched down from the Main Market to AIM between 1997 and 2006; and Panel B for the Up switchers, the 48 firms which switched up from AIM to the Main Market between 1997 and 2006. The first block of numbers in each panel shows statistics of raw returns in event time in the periods surrounding the announcement (thus [-13,-2] refers to the period from 13 weeks prior to the announcement until 2 weeks prior to the announcement). These are the cumulative return in each window, the t-statistic of the cumulative return (computed by dividing the estimated cumulative return by its estimated standard deviation using the cross-section of firms), and for comparison purposes, the cumulative mean return on the FTSE All-Share index in event time. The second block of numbers in each panel presents four factor model adjusted cumulative abnormal returns (CARs) for our sample firms in the windows around the announcement, with their associated t-statistics. The t-statistics for the raw returns are computed using OLS standard errors, and those for the CARs are computed using cross-correlation and heteroskedasticity consistent jackknife standard errors. Cumulative returns that are significant at the $5 \%$ level using the reported T-statistics are in bold, and those significant at the $10 \%$ level are underlined.

Panel A: Down Switchers

\begin{tabular}{lccc}
\hline Raw Returns & {$[-\mathbf{1 3},-\mathbf{2}]$} & {$[-\mathbf{1 , 0 , 1}]$} & {$[+\mathbf{2 , + 1 3 ]}$} \\
\hline Cum. Raw Return & 0.289 & -5.393 & 0.160 \\
OLS T-Statistic & 0.115 & -3.636 & 0.073 \\
Cum. FTSE All-Share Return & 1.238 & 0.145 & 1.581 \\
& & & \\
\hline Risk-Adjusted Returns & {$[\mathbf{- 1 3 , - 2 ]}$} & $\mathbf{[ - 1 , 0 , 1 ]}$ & {$[+\mathbf{+ 2 , + 1 3 ]}$} \\
\hline Cum. Abnormal Return & 0.558 & -4.306 & 2.184 \\
Jackknife T-Statistic & 0.315 & -1.635 & 0.831
\end{tabular}

Panel B: Up Switchers

\begin{tabular}{lccc}
\hline Raw Returns & {$[-\mathbf{1 3 , - 2}]$} & {$[-\mathbf{1 , 0 , 1}]$} & {$[+\mathbf{2 , + 1 3 ]}$} \\
\hline Cum. Raw Return & 3.990 & $\underline{\underline{5.363}}$ & $\underline{\underline{9.828}}$ \\
OLS T-Statistic & 0.931 & 1.777 & 1.892 \\
Cum. FTSE All-Share Return & 1.107 & 0.269 & 0.318 \\
& & & \\
\hline Risk-Adjusted Returns & {$[\mathbf{- 1 3 , - 2 ]}$} & {$[\mathbf{- 1 , 0 , 1 ]}$} & {$[+\mathbf{2 , + 1 3 ]}$} \\
\hline Cum. Abnormal Return & 0.154 & 4.620 & $\mathbf{9 . 9 2 9}$ \\
Jackknife T-Statistic & 0.031 & 1.515 & 2.205
\end{tabular}


Table 5

\section{Four-Factor Model Parameters}

This table presents descriptive statistics on the factor loadings of the firms estimated over [-78,-13] weeks prior to the announcement or switch. The data comprise 210 firms that switched down from the Main Market to AIM between 1997 and 2006; and 48 firms which switched up from AIM to the Main Market between 1997 and 2006. The columns show the intercept, Dimson-corrected betas (with a one week lead and lag), and R-squared statistics from a multiple regression of firm returns on three Fama-French factors constructed using weekly UK data (MKT, SMB and HML), as well as a Momentum factor (UMD). The columns present, in order, the crosssectional mean, median, and standard error of the mean, of these parameters. Panel A presents these data for the Down switchers, and Panel B for the Up switchers.

Panel A: Down Switchers

\section{Parameters Estimated Over [-78,-13]}

Alpha BetaFTSE BetaSMB BetaHML BetaUMD R-squared

\section{Announcement is Week 0}

$\begin{array}{lllllll}\text { Mean } & 0.001 & 0.613 & 0.851 & -0.360 & -0.212 & 0.262 \\ \text { Median } & 0.000 & 0.445 & 0.639 & -0.115 & 0.000 & 0.245 \\ \text { s.e.(Mean) } & 0.001 & 0.079 & 0.164 & 0.154 & 1.386 & \end{array}$

Switch is Week 0

\begin{tabular}{lllllll} 
Mean & 0.000 & 0.695 & 0.800 & -0.227 & 0.568 & 0.255 \\
Median & 0.001 & 0.581 & 0.668 & -0.009 & 0.305 & 0.246 \\
s.e.(Mean) & 0.001 & 0.080 & 0.175 & 0.149 & 1.392 & \\
\hline
\end{tabular}

Panel B: Up Switchers

\begin{tabular}{lcccccc}
\hline & \multicolumn{7}{c}{ Parameters Estimated Over [-78,-13] } \\
& Alpha & BetaFTSE & BetaSMB & BetaHML & BetaUMD & R-squared \\
\hline Announcement is Week 0 & & & & & & \\
Mean & 0.008 & 0.691 & 0.987 & -0.710 & 6.970 & 0.330 \\
Median & 0.006 & 0.404 & 1.007 & -0.254 & 3.671 & 0.338 \\
s.e.(Mean) & 0.003 & 0.218 & 0.509 & 0.485 & 3.901 & \\
Switch is Week 0 & & & & & & \\
Mean & 0.006 & 0.895 & 0.554 & -0.853 & 4.388 & 0.333 \\
Median & 0.004 & 0.837 & 0.569 & -0.463 & 3.375 & 0.335 \\
s.e.(Mean) & 0.003 & 0.219 & 0.489 & 0.469 & 4.863 & \\
\hline
\end{tabular}


Table 6

\section{The Post-Switch Drift}

This table presents the returns in event time for our sample firms in the year following their switch between market segments. Panel A shows the results for the Down switchers, comprising 210 firms which switched down from the Main Market to AIM between 1997 and 2006; and Panel B for the Up switchers, the 48 firms which switched up from AIM to the Main Market between 1997 and 2006. The first block of numbers in each panel shows statistics of raw returns in the four quarters following the switch (thus Q4 ends 52 weeks after the switch). These are the cumulative return in each window, the t-statistic of the cumulative return (computed by dividing the estimated cumulative return by its estimated standard deviation using the cross-section of firms), and for comparison purposes, the cumulative mean return on the FTSE All share index in event time. Cumulative returns that are significant at the 5\% level are in bold, and those significant at the $10 \%$ level are underlined. The second block of numbers in each panel presents mean four factor model adjusted cumulative abnormal returns (CARs) for our sample firms in the four quarters following the switch, with their associated tstatistics. The t-statistics for the raw returns are computed using OLS standard errors, and those for the CARs are computed using cross-correlation and heteroskedasticity consistent jackknife standard errors. Cumulative returns that are significant at the 5\% level using the reported T-statistics are in bold, and those significant at the $10 \%$ level are underlined.

Panel A: Down Switchers

\begin{tabular}{lcccc}
\hline & \multicolumn{4}{c}{ Post-Switch Quarters } \\
Raw Post-Switch Drift & $\mathbf{Q 1}$ & $\mathbf{Q 2}$ & $\mathbf{Q 3}$ & $\mathbf{Q 4}$ \\
\hline Cum. Raw Return & $\mathbf{8 . 2 5 1}$ & $\mathbf{6 . 9 6 2}$ & 0.891 & 3.109 \\
OLS T-Statistic & 2.155 & 3.225 & 0.431 & 2.252 \\
Cum. FTSE Return & 0.998 & 2.236 & 1.680 & 1.741 \\
\hline Risk-Adjusted Post-Switch Drift & $\mathbf{Q 1}$ & $\mathbf{Q 2}$ & $\mathbf{Q 3}$ & $\mathbf{Q 4}$ \\
\hline Cum. Abnormal Return & $\mathbf{8 . 7 7 3}$ & $\mathbf{8 . 4 5 6}$ & $\underline{3.979}$ & 3.015 \\
Jackknife T-statistic & 2.675 & 3.233 & 1.866 & 1.375
\end{tabular}

Panel B: Up Switchers

\begin{tabular}{lcccc}
\hline & \multicolumn{4}{c}{ Post-Switch Quarters } \\
Raw Post-Switch Drift & Q1 & Q2 & Q3 & Q4 \\
\hline Cum. Raw Return & -4.519 & -0.764 & -2.742 & $\mathbf{1 0 . 9 6 9}$ \\
OLS T-Statistic & -0.948 & -0.210 & -0.581 & 2.413 \\
Cum. FTSE Return & -0.049 & 2.162 & 1.622 & 1.509 \\
\hline Risk-Adjusted Post-Switch Drift & $\mathbf{Q 1}$ & $\mathbf{Q 2}$ & $\mathbf{Q 3}$ & $\mathbf{Q 4}$ \\
\hline Cum. Abnormal Return & -10.009 & -5.340 & -4.754 & 8.314 \\
Jackknife T-statistic & -1.426 & -0.980 & -0.602 & 0.893
\end{tabular}


Table 7

Post-Switch Drift, No Index Inclusions or Deletions

This table presents four factor model adjusted cumulative abnormal returns for our sample firms in the year following their switch between market segments. Panel A shows the results for the Down switchers, comprising 210 firms which switched down from the Main Market to AIM between 1997 and 2006; and Panel B for the Up switchers, the 48 firms which switched up from AIM to the Main Market between 1997 and 2006. We set returns in the three week period surrounding index addition and deletion events (i.e., a [-1,0,1] window around such events) to zero. The indices we consider are the FTSE AIM, FTSE Fledgling, FTSE Small Cap, FTSE All Share, FTSE 250 and the Hoare-Govett Small Companies Index, which together constitute the main small companies indices in the UK. The block of numbers in each panel shows the cumulative abnormal returns (CARs) in the four quarters following the switch (thus Q4 ends 52 weeks after the switch) once the above restriction has been imposed. T-statistics for the CARs are computed using cross-correlation and heteroskedasticity consistent jackknife standard errors. Cumulative returns that are significant at the $5 \%$ level using the reported T-statistics are in bold, and those significant at the 10\% level are underlined.

\section{Panel A: Down Switchers}

\begin{tabular}{|c|c|c|c|c|}
\hline \multirow[b]{2}{*}{ Post-Switch Drift } & \multicolumn{4}{|c|}{ Post-Switch Quarters } \\
\hline & Q1 & Q2 & Q3 & Q4 \\
\hline \multicolumn{5}{|l|}{ Switch is Week 0} \\
\hline \multirow[t]{2}{*}{ Cumulative Abnormal Returns } & 9.951 & 8.079 & $\underline{\underline{3.735}}$ & 3.015 \\
\hline & 2.958 & 2.864 & 1.772 & 1.375 \\
\hline Percent of Sample Removed for Additions & 5.275 & & & \\
\hline Percent of Sample Removed for Deletions & 10.347 & & & \\
\hline \multicolumn{5}{|c|}{ Panel B: Up Switchers } \\
\hline & \multicolumn{4}{|c|}{ Post-Switch Quarters } \\
\hline Post-Switch Drift & Q1 & Q2 & Q3 & Q4 \\
\hline \multicolumn{5}{|l|}{ Switch is Week 0} \\
\hline \multirow[t]{2}{*}{$\overline{\text { Cumulative Abnormal Returns }}$} & -10.970 & -4.729 & -3.864 & 8.314 \\
\hline & -1.636 & -0.928 & -0.498 & 0.893 \\
\hline Percent of Sample Removed for Additions & 3.671 & & & \\
\hline Percent of Sample Removed for Deletions & 9.226 & & & \\
\hline
\end{tabular}


Table 8

Operating Performance around the Switch

This table presents statistics on operating performance in the years surrounding the year when firms switch market segments. The sample comprises 213 firms which switched down from the Main Market to AIM between 1997 and 2006; and 51 firms which switched up from AIM to the Main Market between 1997 and 2006, for which data on earnings before interest, taxes, depreciation and amortization (EBITDA) and Total Assets are available in the last complete fiscal year prior to the switch. We present statistics of these data in the $[-2,+2]$ fiscal year window surrounding the switch (year 0 is the last complete fiscal year prior to the fiscal year in which the firm switched market segments). The rows show, in order, the number of firms for which data are available in each fiscal year; Mean Total Assets; Mean EBITDA; Mean EBITDA/Total Assets, winsorized at the $5^{\text {th }}$ and $95^{\text {th }}$ percentiles to mitigate the effect of outliers; and Mean EBITDA/Total Assets, winsorized at the $5^{\text {th }}$ and $95^{\text {th }}$ percentiles to mitigate the effect of outliers, and weighted by Total Assets. Cross-sectional Tstatistics computed using White heteroskedasticity consistent standard errors are reported below coefficients in italics. Panel A presents these data for the Down switchers, and Panel B for the Up switchers. Numbers significant at the $5 \%$ level using the reported T-statistics are in bold, and those significant at the $10 \%$ level are underlined.

Panel A: Down Switchers

\begin{tabular}{|c|c|c|c|c|c|}
\hline & \multicolumn{5}{|c|}{ Fiscal Year Relative to Switch } \\
\hline & -2 & -1 & $\mathbf{0}$ & 1 & 2 \\
\hline $\mathbf{N}($ Firms) & 213 & 211 & 211 & 195 & 177 \\
\hline \multirow[t]{2}{*}{ Mean Total Assets (EMM) } & 47.448 & 46.872 & 45.845 & 46.495 & 48.305 \\
\hline & 5.900 & 7.058 & 8.516 & 10.553 & 11.375 \\
\hline \multirow[t]{2}{*}{ Mean EBITDA (EMM) } & 1.429 & 1.007 & -0.018 & 2.299 & 4.220 \\
\hline & 0.725 & 0.760 & 1.084 & 0.672 & 0.995 \\
\hline \multirow[t]{2}{*}{ EBITDA/Total Assets (\%, Equal Weighted) } & $\underline{\underline{1.653}}$ & $\underline{\underline{1.076}}$ & $\underline{\underline{0.389}}$ & 0.862 & $\underline{\underline{5.419}}$ \\
\hline & 1.873 & 1.874 & 1.785 & 2.009 & 1.768 \\
\hline \multirow[t]{2}{*}{ EBITDA/Total Assets (\%, Asset Wtd) } & 3.544 & 2.889 & $\underline{\underline{1.377}}$ & 5.403 & 8.761 \\
\hline & 1.473 & 1.485 & 1.881 & 1.385 & 2.096 \\
\hline \multicolumn{6}{|c|}{ Panel B: Up Switchers } \\
\hline & \multicolumn{5}{|c|}{ Fiscal Year Relative to Switch } \\
\hline & -2 & -1 & $\mathbf{0}$ & 1 & 2 \\
\hline N(Firms) & 36 & 47 & 51 & 51 & 49 \\
\hline \multirow[t]{2}{*}{ Mean Total Assets (£MM) } & 32.610 & 49.528 & 63.953 & 160.043 & 177.621 \\
\hline & 2.346 & 3.923 & 6.537 & 2.801 & 2.779 \\
\hline \multirow[t]{2}{*}{ Mean EBITDA (EMM) } & 0.422 & $\underline{\underline{5.149}}$ & 3.480 & 9.375 & $\underline{\underline{12.025}}$ \\
\hline & 0.309 & 1.740 & 2.579 & 2.107 & 1.779 \\
\hline \multirow[t]{2}{*}{ EBITDA/Total Assets (\%, Equal Weighted) } & -5.586 & 0.203 & 2.234 & 2.567 & -2.812 \\
\hline & -1.276 & 0.057 & 0.686 & 0.877 & -0.686 \\
\hline \multirow[t]{2}{*}{ EBITDA/Total Assets (\%, Asset Wtd) } & 1.281 & $\underline{\underline{9.283}}$ & 5.316 & 5.732 & $\underline{\underline{6.960}}$ \\
\hline & 0.331 & 1.862 & 2.570 & 2.101 & 1.884 \\
\hline
\end{tabular}


Table 9

\section{Does the Post-Switch Drift Forecast Operating Performance?}

This table presents results from cross-sectional regressions to explain operating performance (as measured by EBITDA/Assets) in the second fiscal year following the year in which firms switch market segments. The specifications are estimated only on the Down switchers since there are insufficient observations for the upswitchers given data availability constraints. We denote this variable ROA(Fiscal Year +2 ), and regress it on an intercept; ROA in the past four fiscal years; the log of the firm's Market Capitalization and the log of a firm's Market/Book ratio (Market Capitalization divided by Total Assets) in the last full fiscal year prior to the switch; and the cumulative abnormal returns (CARs) in the three weeks surrounding the announcement, and the twelve months after the switch. This last variable is the post-switch drift. We estimate both an OLS specification, with White heteroskedasticity consistent standard errors, and a Weighted Least Squares (WLS) specification, in which we weight observations by the square root of market capitalization. Coefficients that are significant at the $5 \%$ level using the reported T-statistics are in bold, and those significant at the $10 \%$ level are underlined. The $\mathrm{R}$-squared and number of observations are reported in the last two rows of the table.

\begin{tabular}{lcc}
\hline & \multicolumn{2}{c}{ Down Switchers } \\
ROA(Fiscal Year +2) & OLS & WLS \\
\hline & & \\
Intercept & 0.023 & 0.000 \\
ROA(Fiscal Year +1) & 0.178 & 0.126 \\
& $\mathbf{0 . 2 4 5}$ & $\mathbf{0 . 1 6 2}$ \\
ROA(Fiscal Year 0) & 3.749 & 3.562 \\
ROA(Fiscal Year -1) & $\mathbf{0 . 2 1 1}$ & $\mathbf{0 . 2 9 0}$ \\
& 2.348 & 4.760 \\
ROA(Fiscal Year -2) & $\underline{0.126}$ & 0.067 \\
& 1.720 & 0.945 \\
log(Market Capitalization) (Fiscal Year 0) & 0.061 & $\mathbf{0 . 1 6 7}$ \\
& 0.802 & 2.814 \\
log(Market/Book) (Fiscal Year 0) & 0.002 & \\
& 0.161 & \\
CAR in Announcement Week & -0.002 & 0.007 \\
& -0.198 & 1.539 \\
CAR in 12 Months Following Switch (Drift) & $\underline{\mathbf{0 . 2 9 8}}$ & $\mathbf{0 . 2 1 3}$ \\
& 2.796 & 2.332 \\
R-squared & 1.641 & 2.695 \\
Number of Observations & & \\
& 0.422 & 0.407 \\
& 162 & 162 \\
& &
\end{tabular}




\section{Figure 1}

\section{Performance of the Main Market and AIM, and the Number of Firms Switching Markets}

This figure shows the performance of the Main Market (as measured by the FTSE All Share Index) and AIM (as measured by the FTSE AIM Index), along with the number of companies switching between markets from 1997 until the end of 2006. Both market indices measure total returns, including reinvested dividends. The AIM index was introduced in May 1997. Companies are classified by quarter according to the date of the actual switch.

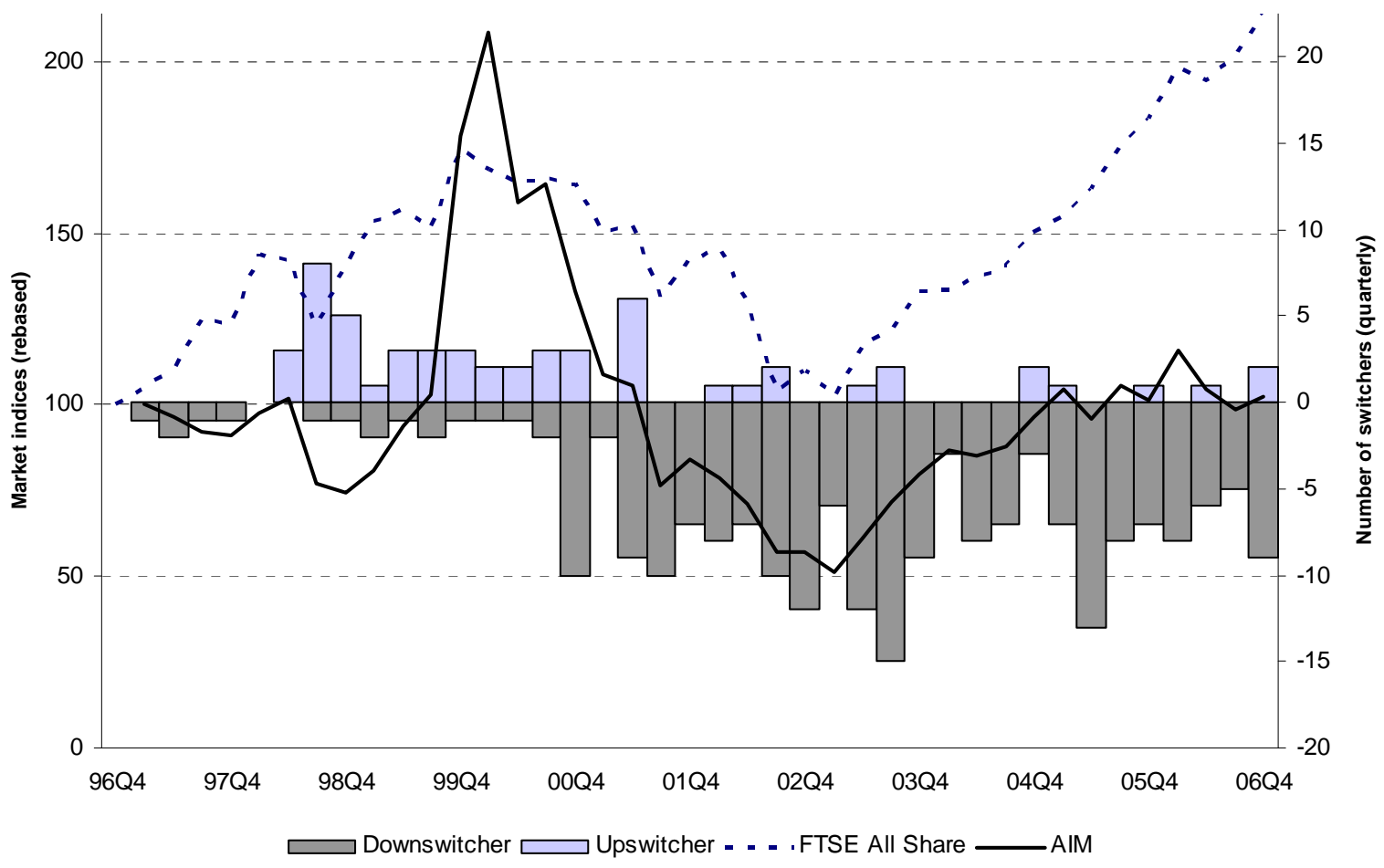


Figure 2

\section{Announcement Date Returns}

Panel A (B) of this figure plots cumulative abnormal returns for the firms switching from the Main Market to AIM (AIM to the Main Market) in our sample, around the announcement dates. The CARs are constructed using four different models: the Fama-French-Carhart four-factor model; a two-factor model comprising the FTSE All Share and FTSE AIM indices; and simple market adjustment using the FTSE All Share and the FTSE AIM indices.

\section{Panel A: Down Switchers}

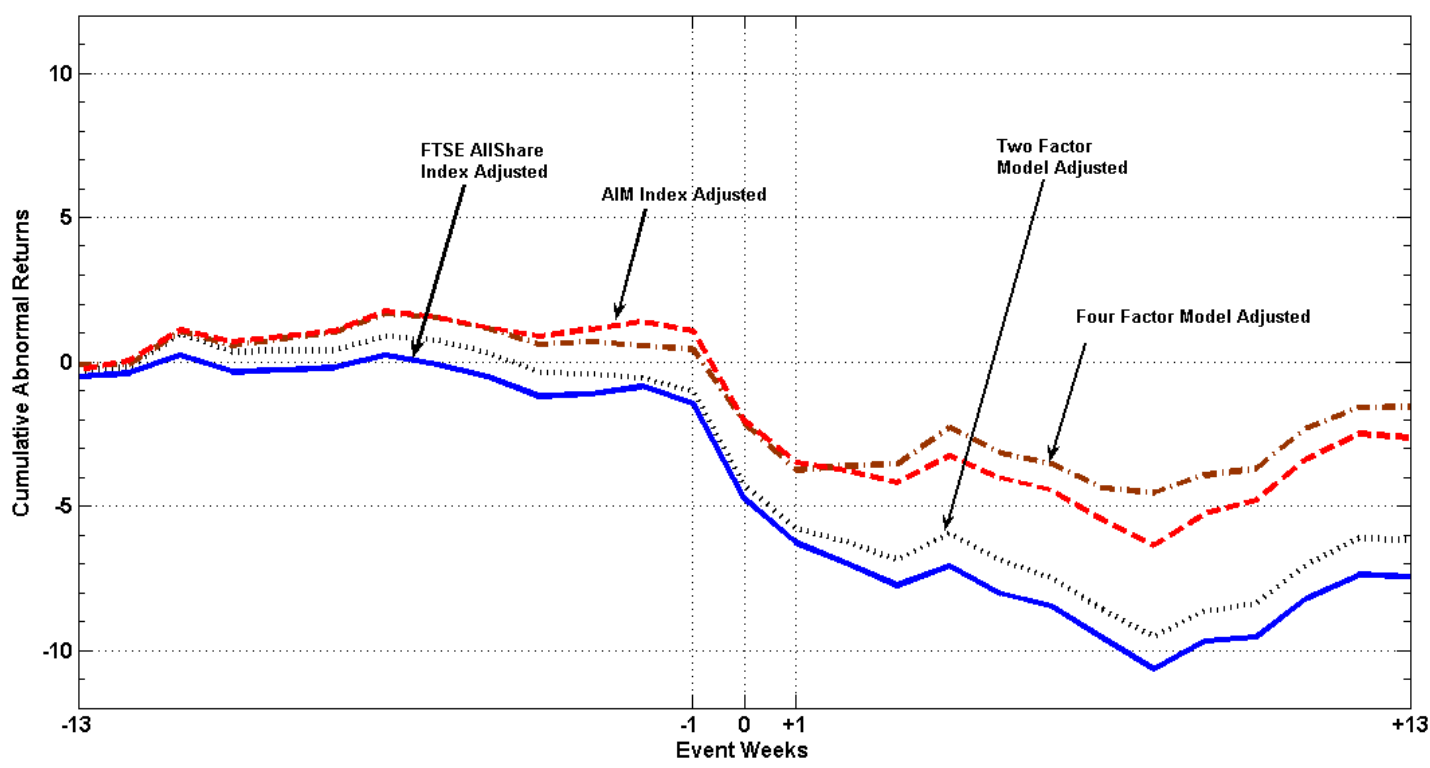

Panel B: Up Switchers

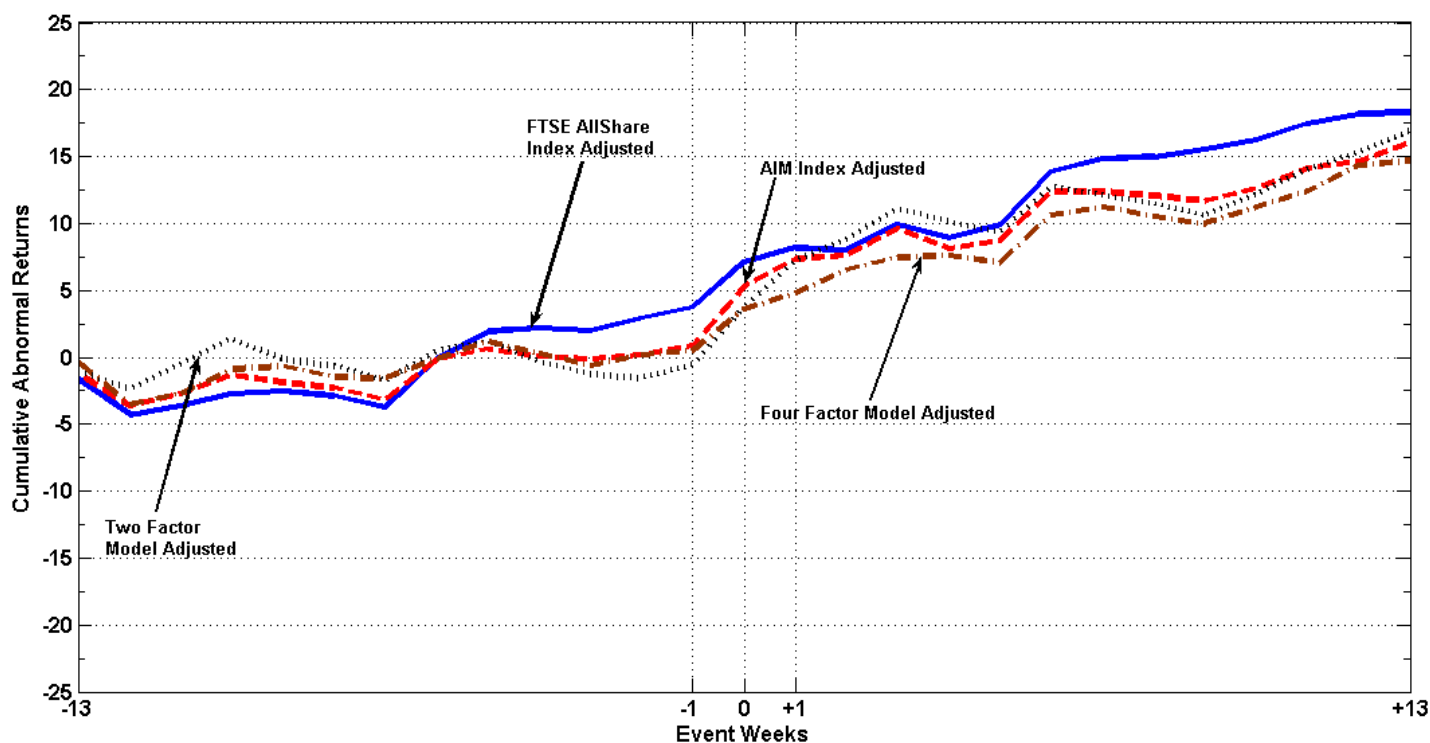




\section{Figure 3 \\ Post-Switch Drift}

Panel A (B) of this figure plots cumulative abnormal returns for the firms switching from the Main Market to AIM (AIM to the Main Market) in our sample, in the year following the switch date. The CARs are constructed using four different models: the Fama-French-Carhart four-factor model; a two-factor model comprising the FTSE All Share and FTSE AIM indices; and simple market adjustment using the FTSE All Share and the FTSE AIM indices.

\section{Panel A: Down Switchers}

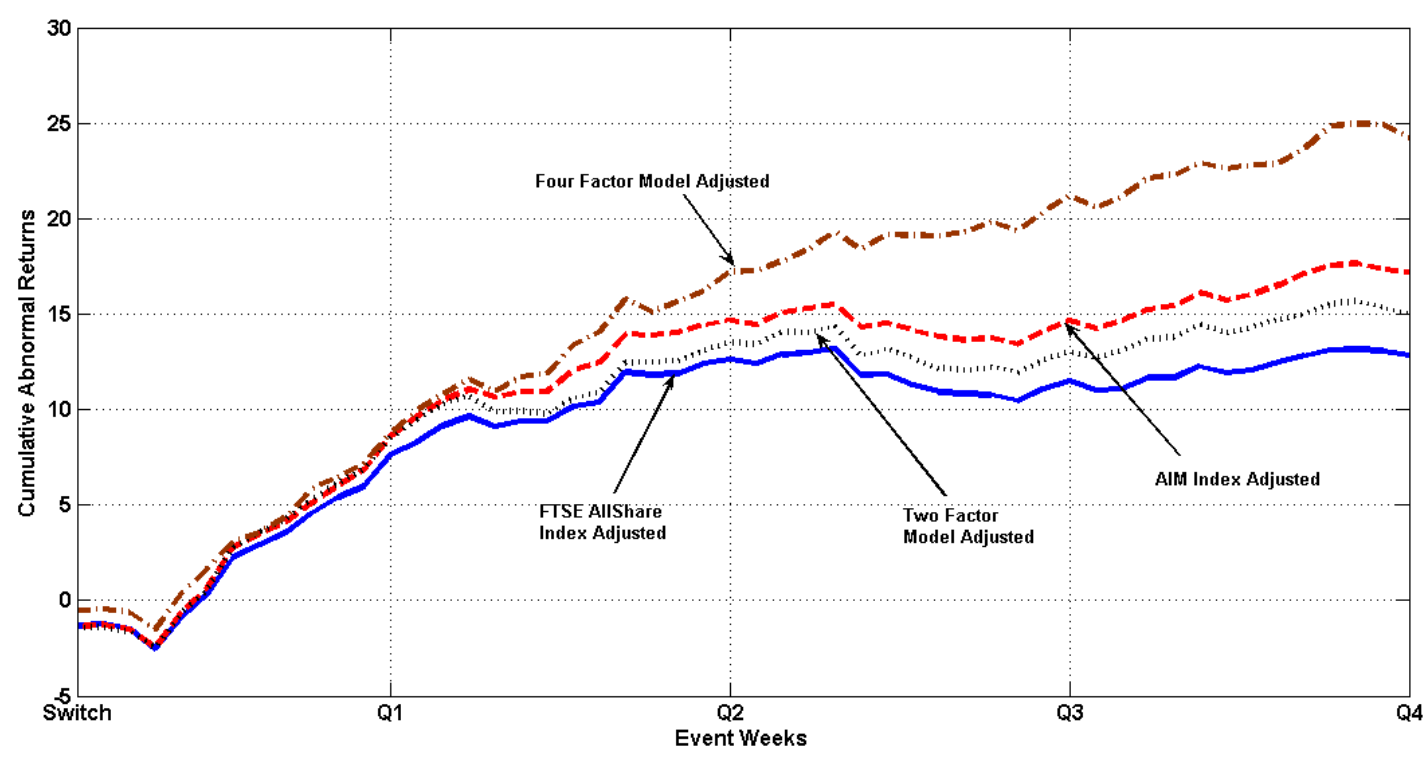

Panel B: Up Switchers

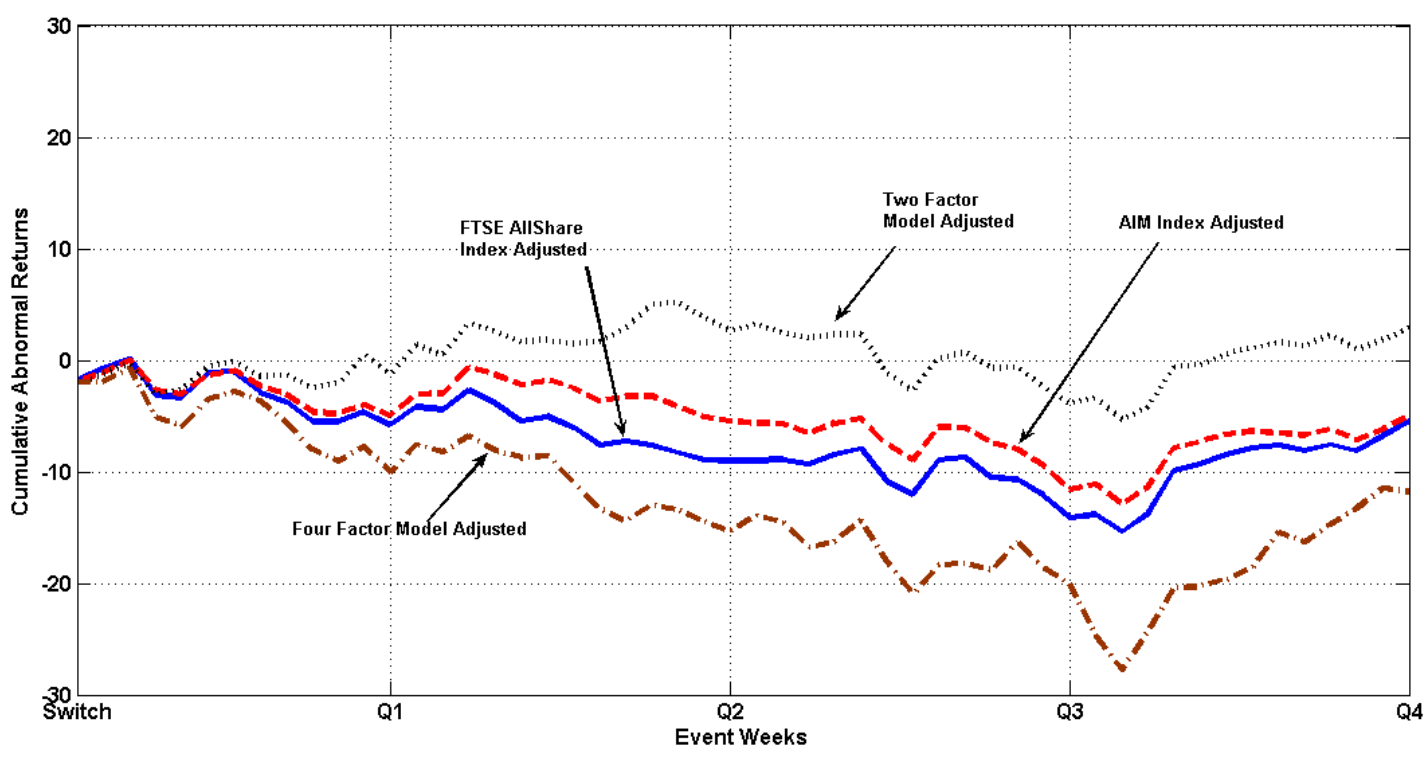




\section{Figure 4 \\ Beneficial Ownership Around the Switch}

Panel A (B) of this figure plots the average ownership of all external beneficial owners (those owning $>3 \%$ of the firm), as well as the ownership by all managers of the firm in Down (Up) switchers in the $[-26,+26]$ week window surrounding the switch. These data come from the Extrahold/Hemscott Database. The ownership statistics are reported separately for individuals and institutional owners.

\section{Panel A: Down Switchers}

Beneficial Ownership Around Down Switch

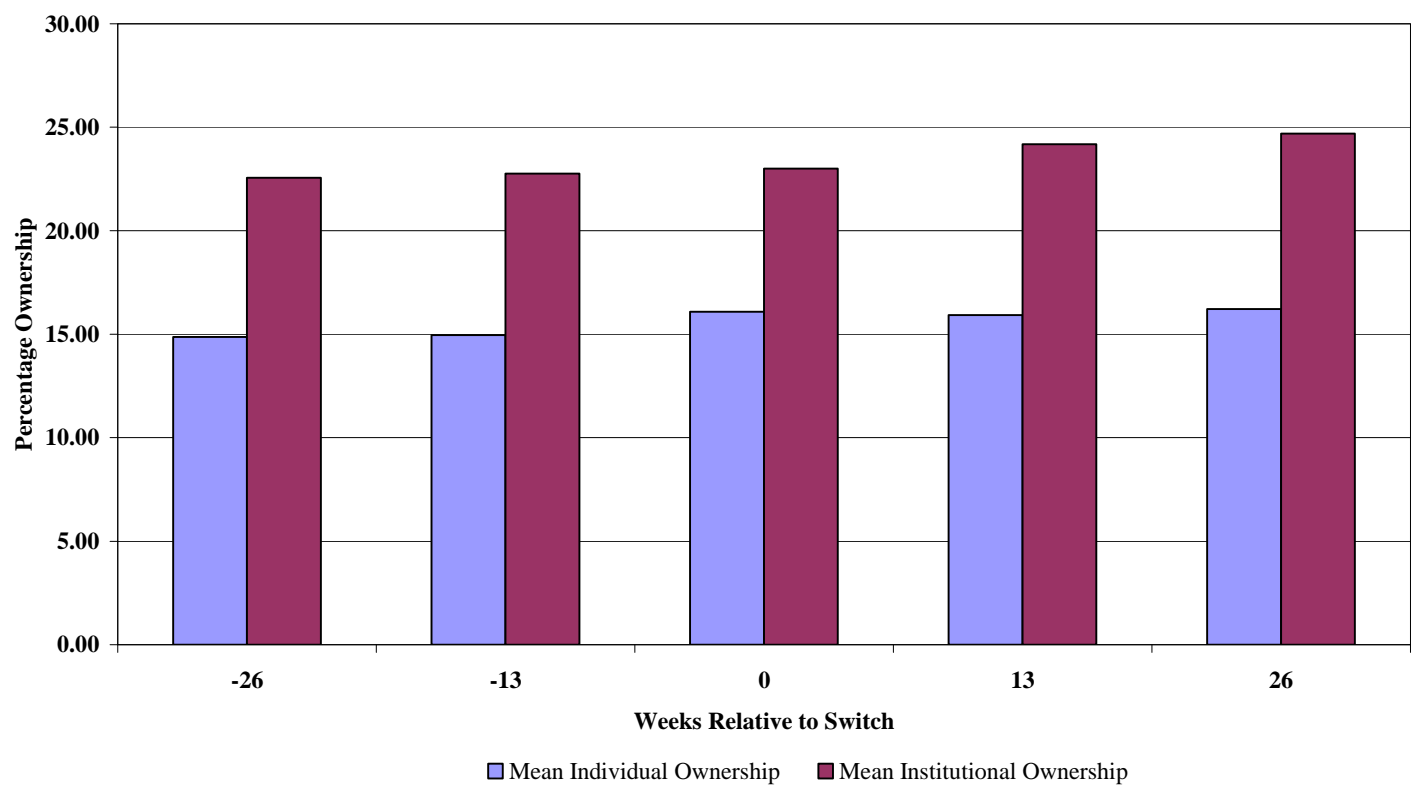

Panel B: Up Switchers

Beneficial Ownership Around Up Switch

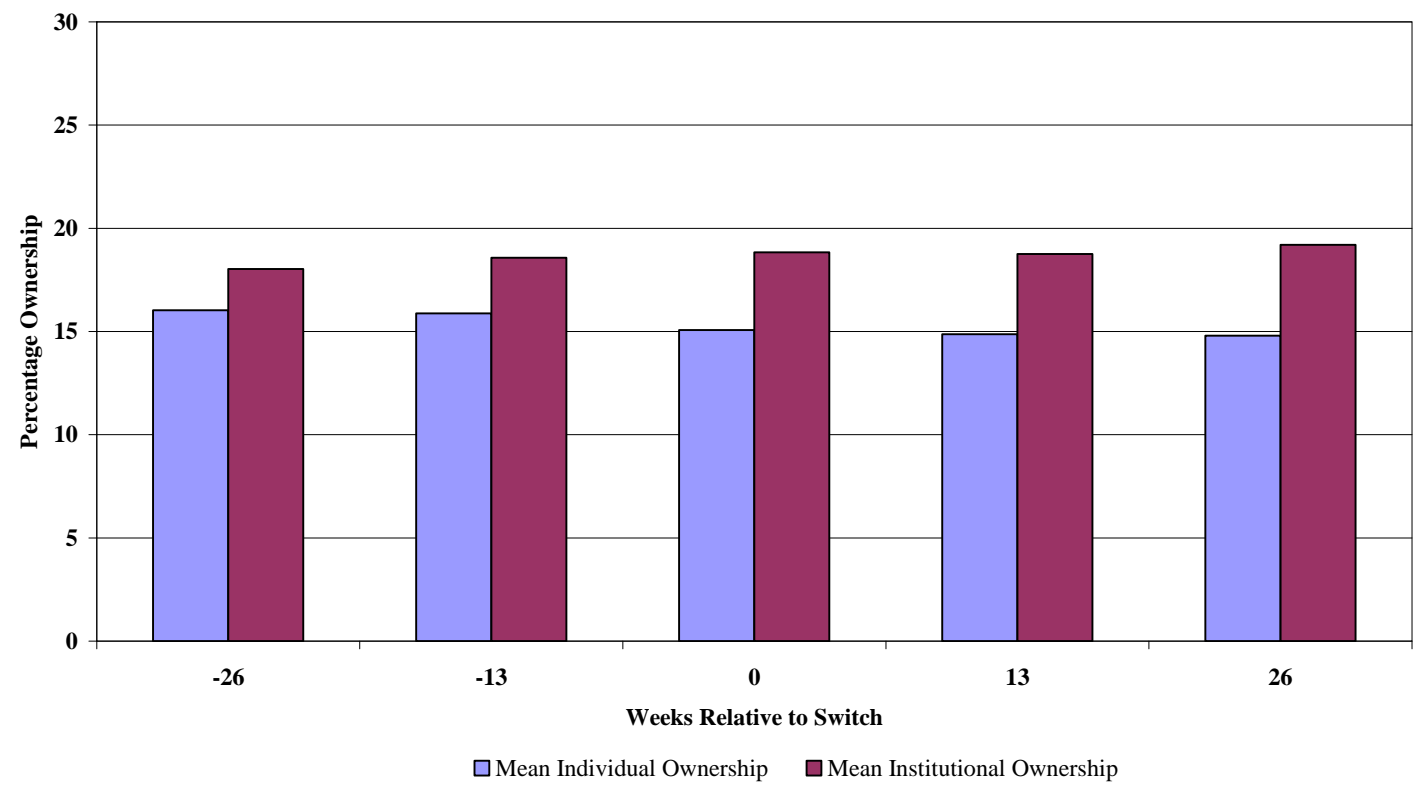


Figure 5

Operating Performance Around the Switch

Panel A (B) of this figure plots the asset-weighted average EBITDA/Total Assets of all Down (Up) switchers in the $[-2,+2]$ fiscal year window surrounding the switch. Fiscal Year 0 is the last full fiscal year prior to the switch. These data are also presented in Table IV, which presents details about their construction.

\section{Panel A: Down Switchers}

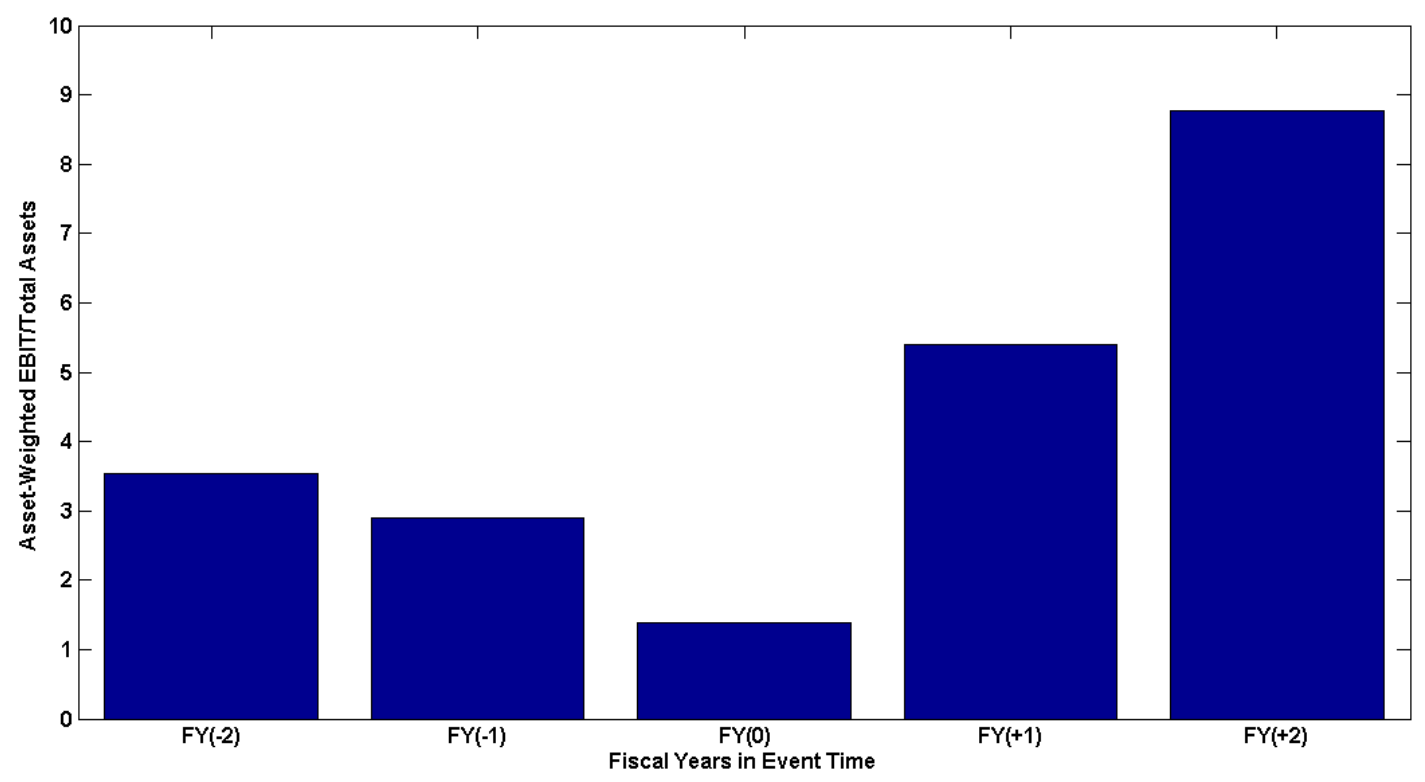

Panel B: Up Switchers

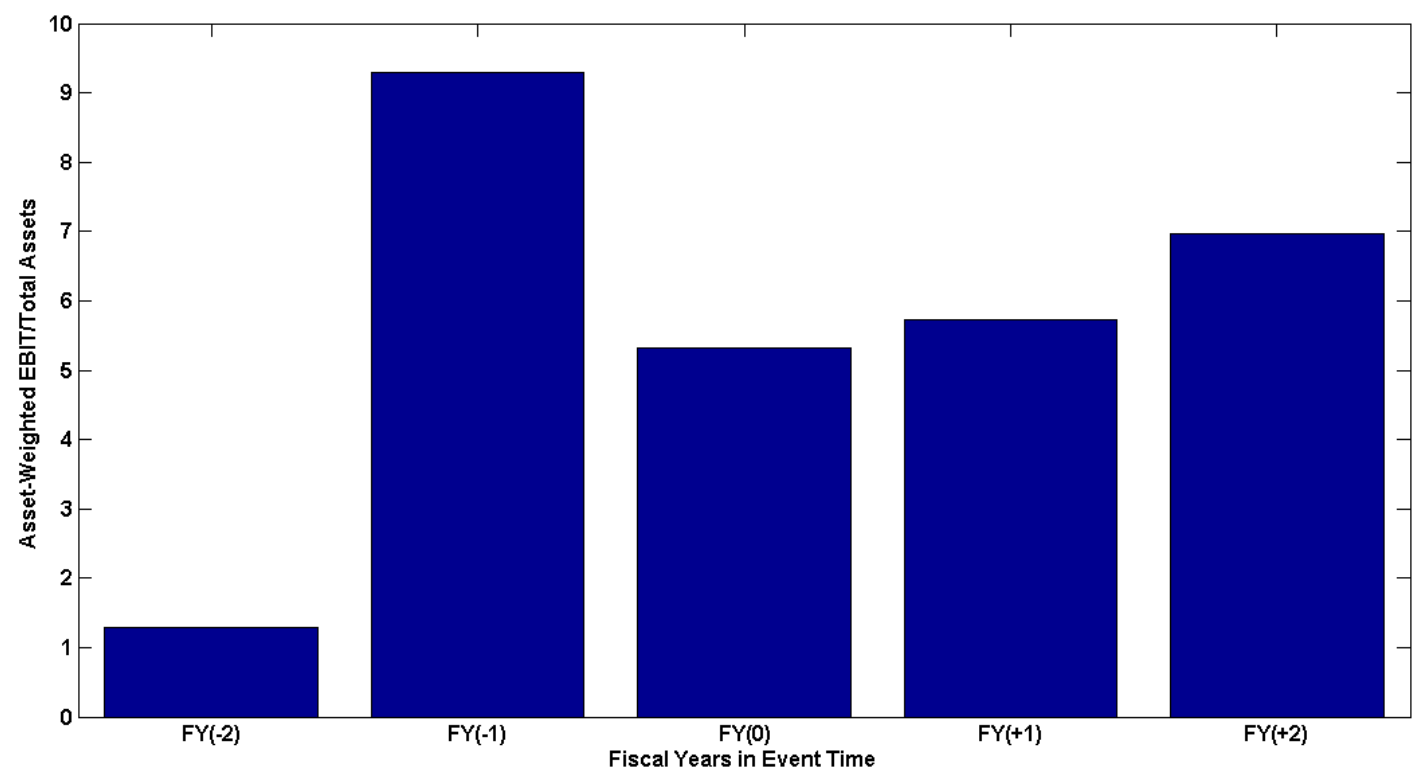

